\title{
Assessment of co-sublimation for the formation of multicomponent crystals
}

\author{
Jean Lombard, Delia A. Haynes and Tanya le Roex \\ Department of Chemistry and Polymer Science, Stellenbosch University, P. Bag X1, Matieland, 7602, \\ Stellenbosch, Republic of South Africa. \\ Supplementary Information
}

Contents

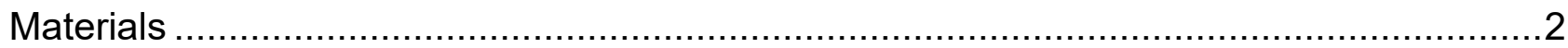

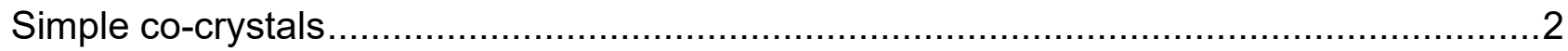

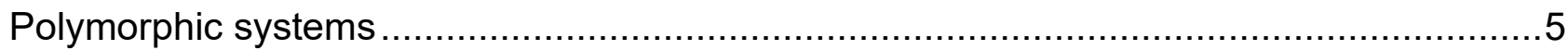

Co-crystallization when molecules have different sublimation temperatures ....................9

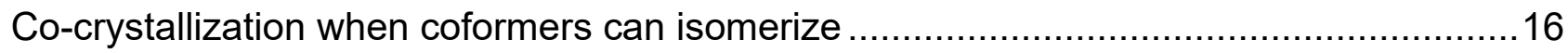

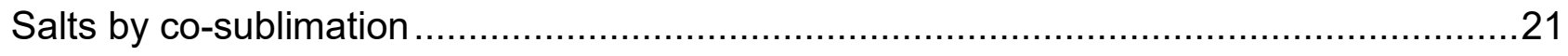

Co-crystallization using heat-sensitive molecules ...............................................21

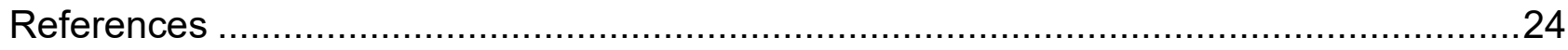




\section{Materials}

Coformer abbreviations: caffeine (CAF), theophylline (THE), nicotinamide (NAM), isonicotinamide (INAM), fumaric acid (FA), maleic acid (MA), benzoic acid (BA), nicotinic acid (NA), succinic acid (SA), salicylic acid (SAL), gallic acid monohydrate (GA), oxalic acid dihydrate (OA), pyridine (PYR), 4,4'-bipyridine (BPY), 4-phenylpyridine (4PP), 3-picoline (3PIC), 2,3-lutidine (23LUT), piperazine (PIP), hexamethylenetetramine (HMT), pyrogallol (PYG).

\section{Simple co-crystals}

\section{CAF and SAL}

The 1:1 co-crystal of caffeine and salicylic acid (1) was formed by grinding caffeine $(0.047 \mathrm{~g}$, $0.24 \mathrm{mmol})$ and salicylic acid $(0.033 \mathrm{~g}, 0.24 \mathrm{mmol})$ together for 20 minutes in a ball mill (neat). Cocrystal 1 could also be formed by sublimation of a 1:1 molar ratio of the starting materials. Caffeine $(0.035 \mathrm{~g}, 0.18 \mathrm{mmol})$ and salicylic acid $(0.025 \mathrm{~g}, 0.18 \mathrm{mmol})$ were added to a thin Schlenk tube and heated in a $140{ }^{\circ} \mathrm{C}$ oil bath for $8 \mathrm{~h}$ under static vacuum. A $2: 1$ or 1:2 ratio could also be used.

\section{$C A F$ and $O A$}

The combination of CAF and OA produced a 2:1 co-crystal (2) in all experiments. Grinding a 2:1 molar ratio of caffeine $(0.060 \mathrm{~g}, 0.31 \mathrm{mmol})$ and oxalic acid $(0.020 \mathrm{~g}, 0.16 \mathrm{mmol})$, with the addition of $20 \mu \mathrm{l}$ of methanol, led to the formation of co-crystal 2 (Figure S1). Co-subliming CAF (0.045 g, $0.23 \mathrm{mmol})$ and $\mathrm{OA}(0.015 \mathrm{~g}, 0.12 \mathrm{mmol})$ at $120^{\circ} \mathrm{C}$ for $24 \mathrm{~h}$ under static vacuum led to the formation of fine crystals of $\mathbf{2}$. A band of OA crystals also formed higher up in the sublimation tube and could be removed separately from the co-crystals. Additionally, water droplets condensed in the cap of the tube, as the dihydrate of OA was used as the starting material. A 1:1 or 1:2 ratio could also be used. 


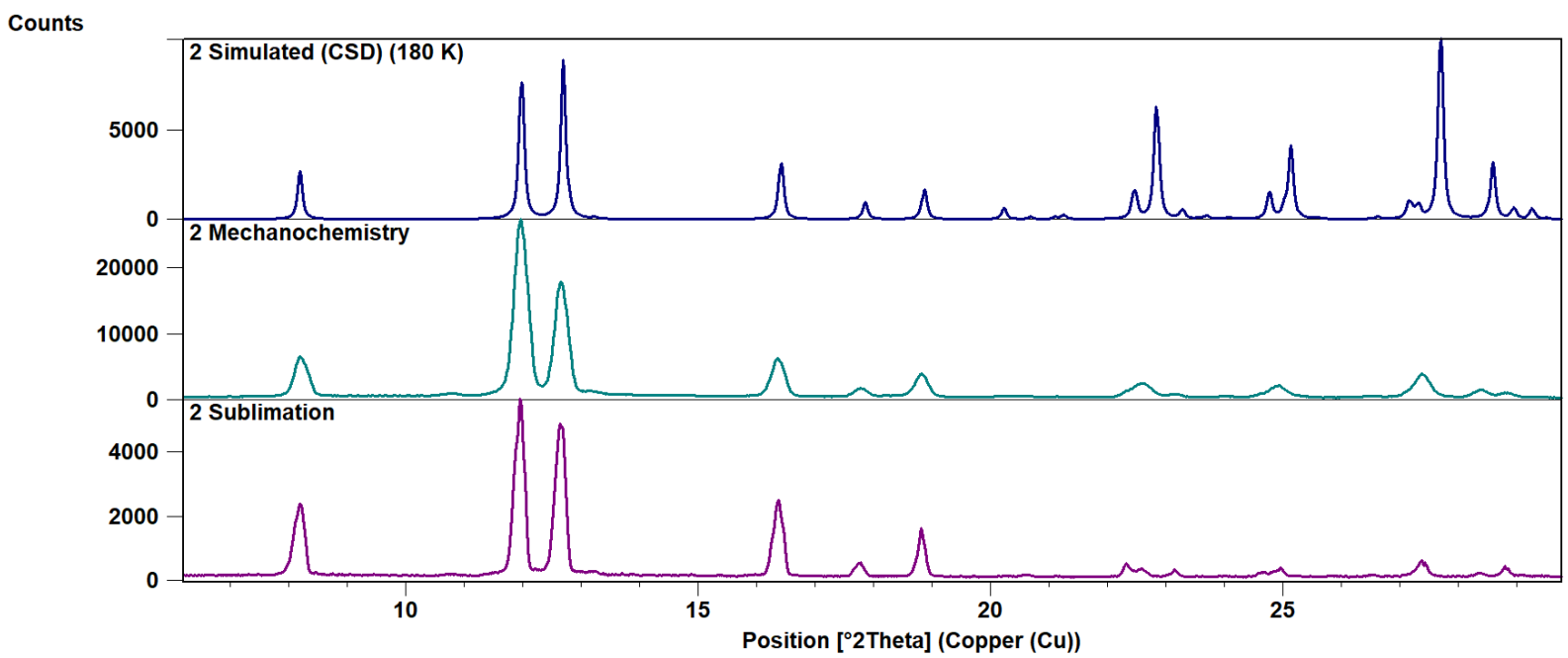

Figure S1. Comparison of the experimental powder patterns of 2 (obtained from LAG and cosublimation) to the pattern simulated from single-crystal data obtained from the CSD (refcode GANXUP) ${ }^{2}$.

\section{THE and SAL}

The combination of THE and SAL produced a 1:1 co-crystal (3) in all experiments. Grinding theophylline $(0.045 \mathrm{~g}, 0.25 \mathrm{mmol})$ and salicylic acid $(0.035 \mathrm{~g}, 0.25 \mathrm{mmol})$ in a $1: 1$ molar ratio for 20 minutes with $20 \mu 1$ of methanol led to complete conversion to the co-crystal (3) (Figure S2). Subliming a 1:1 molar ratio of THE $(0.034 \mathrm{~g}, 0.19 \mathrm{mmol})$ and SAL $(0.026 \mathrm{~g}, 0.19 \mathrm{mmol})$ at $140{ }^{\circ} \mathrm{C}$ under static vacuum $(14 \mathrm{~h})$ led to the formation of polycrystalline 3. SAL is more volatile than THE, and crystals of pure SAL were found to form in the cooler part of the sublimation tube (high in the tube). Conversely, THE crystallized at the bottom of the tube. The co-crystal formed just above the band of theophylline crystals, with slight overlap between these two bands. A 2:1 or 1:2 ratio could also be used. 


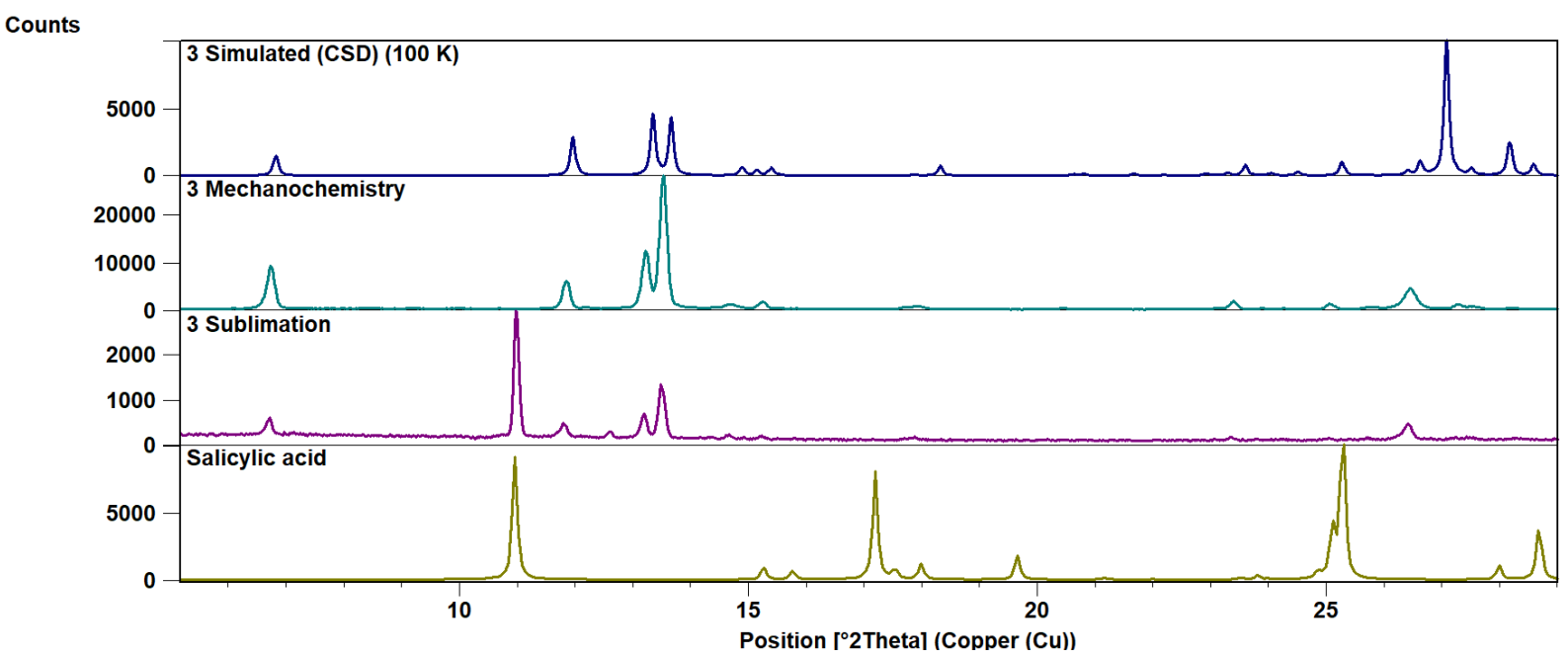

Figure S2. Comparison of the experimental powder patterns of 3 (obtained from LAG and cosublimation) to the pattern simulated from single-crystal data obtained from the CSD (refcode KIGLES) ${ }^{3}$. The product obtained from sublimation is not pure. Some of the impurity peaks correspond to salicylic acid.

\section{THE and $O A$}

The combination of THE and OA produced a 2:1 co-crystal (4) in all experiments. Grinding a 2:1 molar ratio of theophylline $(0.059 \mathrm{~g}, 0.33 \mathrm{mmol})$ and oxalic acid $(0.021 \mathrm{~g}, 0.16 \mathrm{mmol})$ in $20 \mu \mathrm{lof}$ methanol together for 20 minutes in a ball mill produced the co-crystal 4 (Figure S3). Co-subliming a mixture of THE $(0.044 \mathrm{~g}, 0.24 \mathrm{mmol})$ and $\mathrm{OA}(0.015 \mathrm{~g}, 0.12 \mathrm{mmol})$ at $160{ }^{\circ} \mathrm{C}(24 \mathrm{~h}$, static vacuum $)$ also produced pure 4 in between OA (top) and THE crystals (bottom).

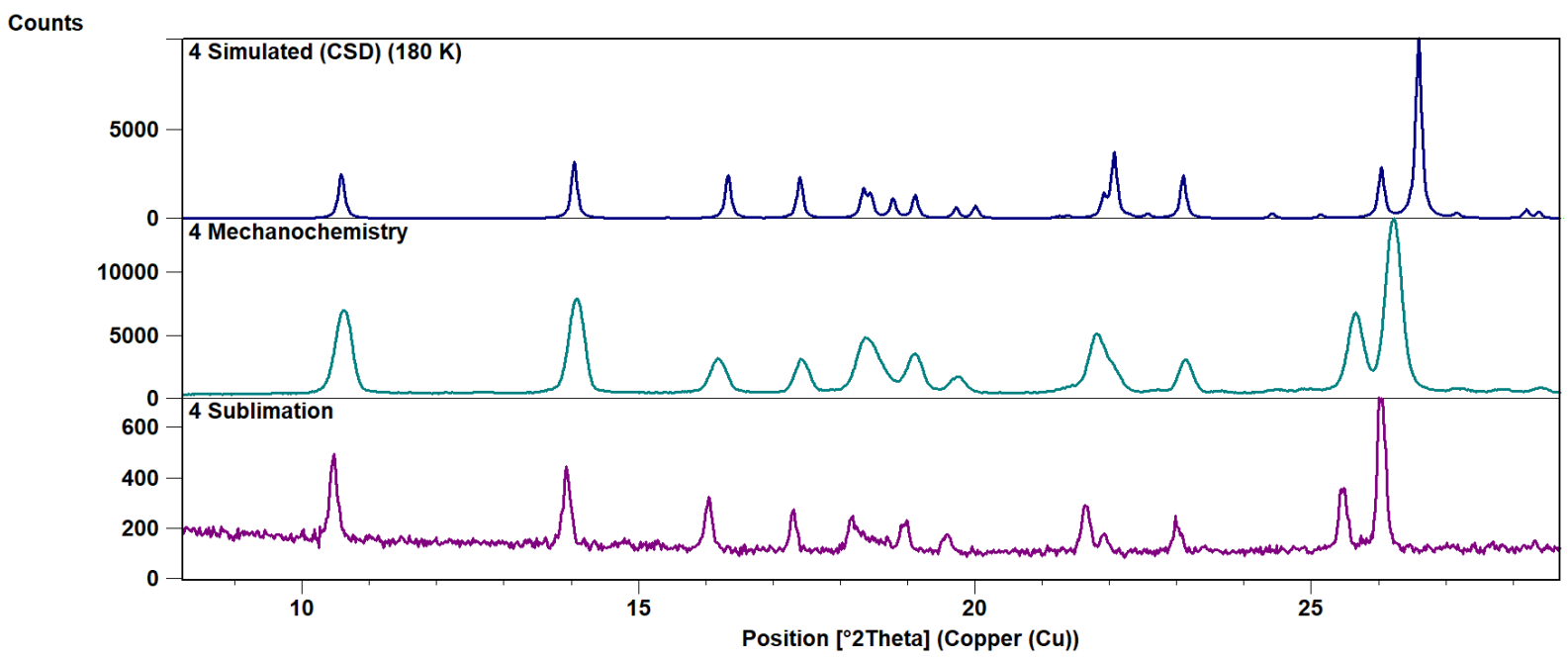

Figure S3. Comparison of the experimental powder patterns of 4 (obtained from LAG and cosublimation) to the pattern simulated from single-crystal data obtained from the CSD (refcode XEJWUF) $)^{4}$. 


\section{THE and INAM}

The combination of THE and INAM produced a 1:1 co-crystal (5) in all experiments. Grinding a 1:1 molar ratio of theophylline $(0.060 \mathrm{~g}, 0.33 \mathrm{mmol})$ and isonicotinamide $(0.040 \mathrm{~g}, 0.33 \mathrm{mmol})$ with $25 \mu \mathrm{l}$ of methanol for 20 minutes produced the co-crystal 5 (Figure S4). Co-subliming a 1:1 molar ratio of THE $(0.080 \mathrm{~g}, 0.44 \mathrm{mmol})$ and INAM $(0.054 \mathrm{~g}, 0.44 \mathrm{mmol})$ at $120^{\circ} \mathrm{C}(8 \mathrm{~h}$, static vacuum $)$ produced 5 as a band of powder below a band of INAM (the more volatile coformer).

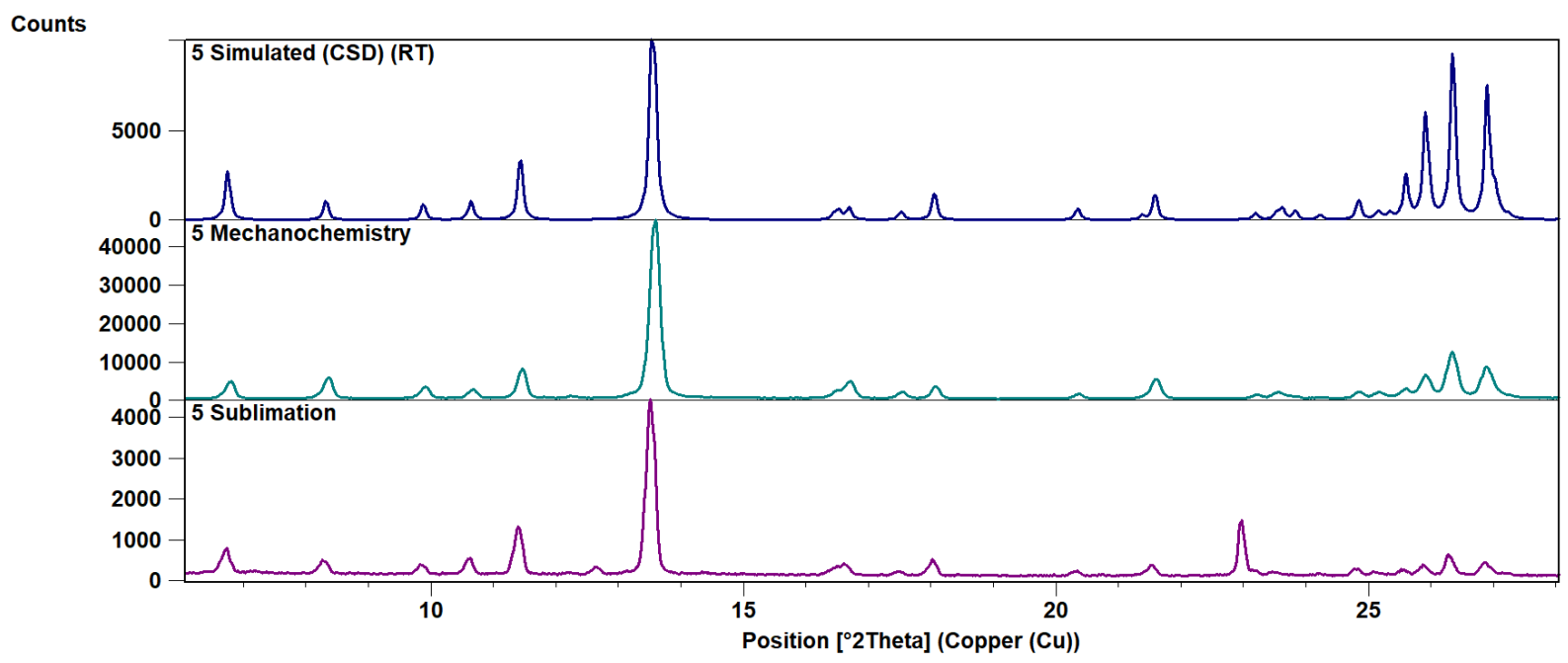

Figure S4. Comparison of the experimental powder patterns of 5 (obtained from LAG and cosublimation) to the pattern simulated from single-crystal data obtained from the CSD (refcode EVEYAH) ${ }^{5}$.

\section{Polymorphic systems}

\section{FA and 23LUT}

The 1:2 co-crystal of fumaric acid and 2,3-lutidine (6a) was made by grinding FA (0.035 g, $0.30 \mathrm{mmol}$ ) and 23LUT ( $69 \mu 1,0.60 \mathrm{mmol})$ together for 20 minutes in a ball mill (neat) (Figure S5). The 2:1 co-crystal salt polymorphs of fumaric acid and 2,3-lutidine (6b I and $\mathbf{6 b}$ II) were made as a mixture by grinding FA $(0.069 \mathrm{~g}, 0.59 \mathrm{mmol})$ and 23LUT (34 $\mu 1,0.30 \mathrm{mmol})$ together for 20 minutes in a ball mill (neat) (Figure S7).

The new polymorph (6b II) could be obtained by heating FA (0.040 g, $0.34 \mathrm{mmol})$ and 23LUT (39 $\mu 1,0.34 \mathrm{mmol}$ ) together for 2 hours in a test tube at $125^{\circ} \mathrm{C}$. 


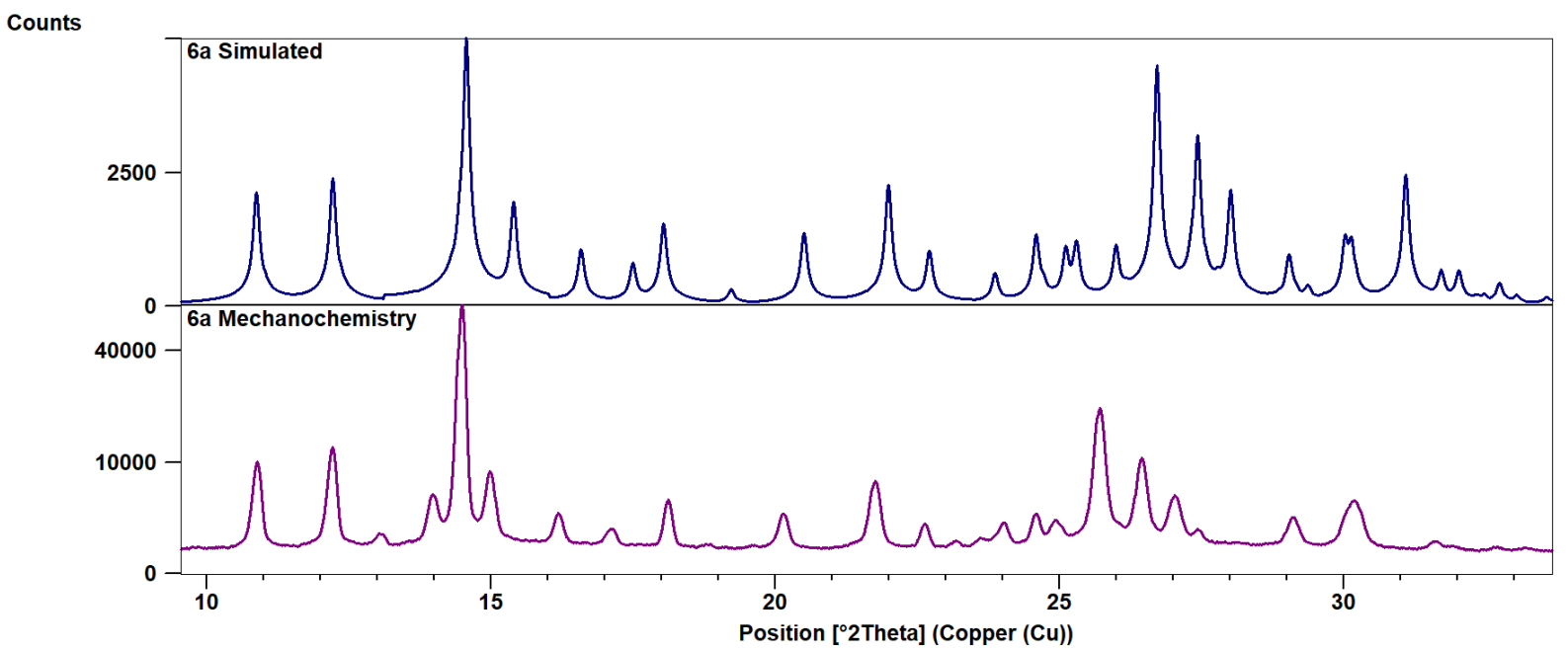

Figure S5. Comparison of the experimental powder pattern of $\mathbf{6 a}$, obtained from neat grinding, to the pattern simulated from single-crystal data obtained from the CSD (refcode RESFOL) ${ }^{6}$.

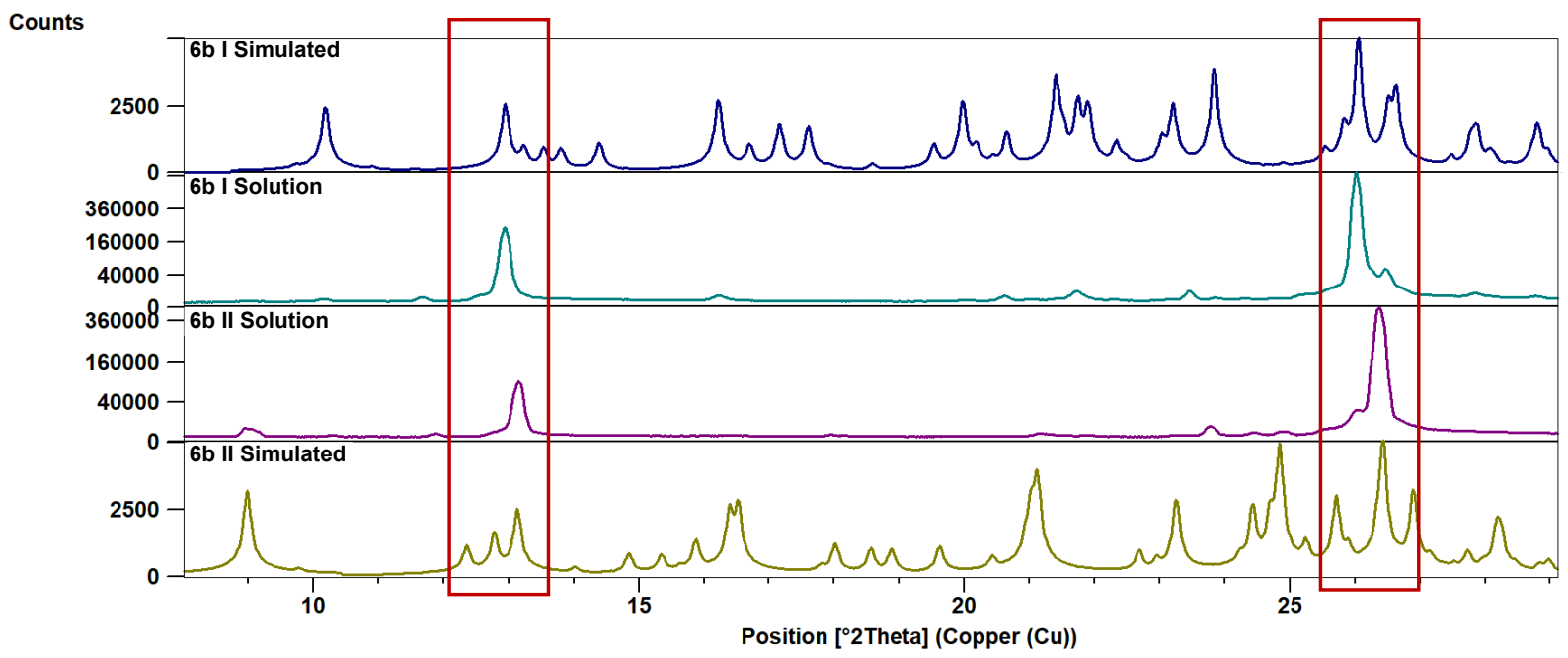

Figure S6. PXRD patterns for $6 \mathbf{b}$ I and $6 \mathbf{b}$ II obtained from solution. It is challenging to distinguish between 6b I and 6b II due to facial selectivity - samples cannot be ground before analysis as the polymorphs interconvert in the process. The indicated peaks are used primarily to distinguish between the two forms. 


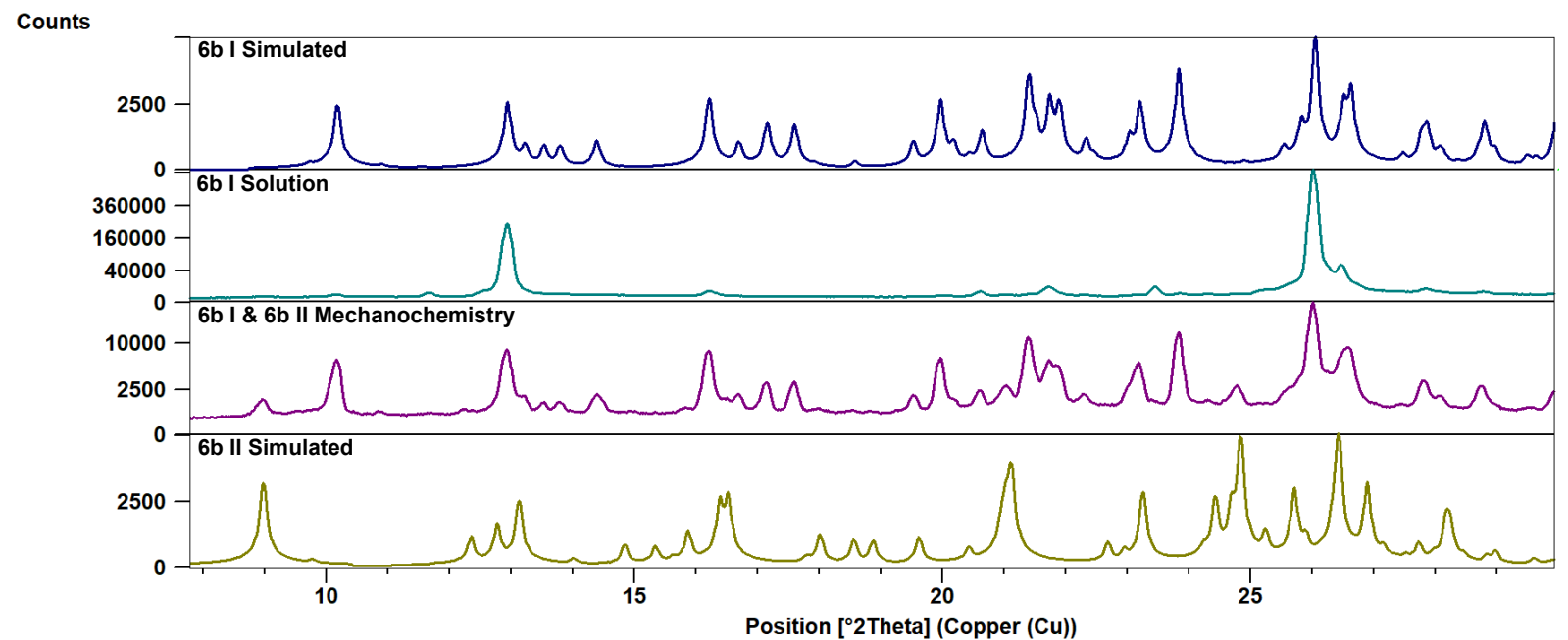

Figure S7. Comparison of the experimental powder pattern, obtained from grinding FUM and 23LUT, to the simulated powder patterns shows that the formation of $\mathbf{6 b} \mathbf{~ I ~ m e c h a n o c h e m i c a l l y ~ i s ~}$ always accompanied by the formation of $\mathbf{6 b}$ II.

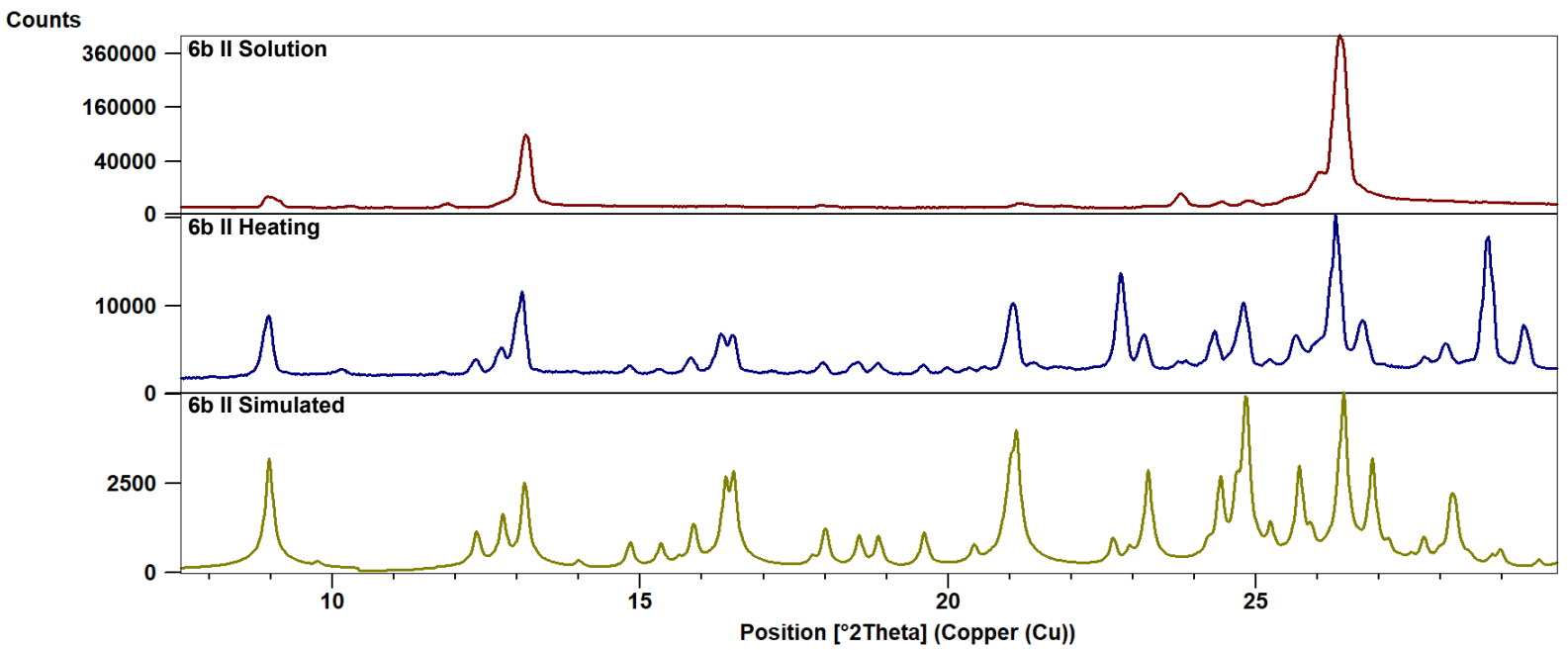

Figure S8. Comparison of the experimental powder patterns of $6 \mathbf{b}$ II (obtained from solution crystallization or heating the starting materials together) to the pattern simulated from single-crystal data collected for this study. 1

All three multicomponent crystals (6a, 6b I, 6b II) could also be formed by sublimation of a 2:1 molar ratio of the starting materials. FA $(0.069 \mathrm{~g}, 0.59 \mathrm{mmol})$ and 23LUT $(34 \mu 1,0.30 \mathrm{mmol})$ were added to a large Schlenk tube and heated in a $140{ }^{\circ} \mathrm{C}$ oil bath for $24 \mathrm{~h}$ under static vacuum. Crystals of $6 \mathbf{b}$ I and $6 \mathbf{b}$ II formed alongside polycrystalline $6 \mathbf{a}$. 
Table S1. Crystallographic data for the co-crystal 6a and the co-crystal salts $6 \mathbf{b}$ I and $6 \mathbf{b}$ II.

\begin{tabular}{|c|c|c|c|}
\hline Structure & 6a & 6b I & 6b II \\
\hline Chemical formula & $\mathrm{C}_{18} \mathrm{H}_{22} \mathrm{~N}_{2} \mathrm{O}_{8}$ & $\mathrm{C}_{15} \mathrm{H}_{17} \mathrm{NO}_{8}$ & $\mathrm{C}_{15} \mathrm{H}_{17} \mathrm{NO}_{8}$ \\
\hline Formula weight $/ \mathrm{g} \mathrm{mol}^{-1}$ & 330.37 & 339.29 & 339.29 \\
\hline Crystal system & monoclinic & monoclinic & monoclinic \\
\hline Space group & $P 2_{1} / n$ & $P 2_{1} / n$ & $P 2_{1} / n$ \\
\hline Temperature /K & $100(2)$ & $100(2)$ & $100(2)$ \\
\hline$a / \AA$ & $9.897(2)$ & $9.025(1)$ & $7.4340(7)$ \\
\hline$b / \AA$ & $7.088(1)$ & $18.151(2)$ & $18.131(2)$ \\
\hline$c / \AA$ & $12.239(2)$ & $9.665(1)$ & $11.656(1)$ \\
\hline$\alpha /{ }^{\circ}$ & 90 & 90 & 90 \\
\hline$\beta /{ }^{\circ}$ & $96.786(3)$ & $90.509(2)$ & $95.628(1)$ \\
\hline$\gamma / 0$ & 90 & 90 & 90 \\
\hline Calc. density $/ \mathrm{g} \mathrm{cm}^{-3}$ & 1.287 & 1.424 & 1.441 \\
\hline Volume $/ \AA^{3}$ & $852.5(3)$ & $1583.0(3)$ & $1563.5(3)$ \\
\hline$Z$ & 2 & 4 & 4 \\
\hline Independent reflections & 1981 & 3691 & 3866 \\
\hline $\mathrm{R}_{\mathrm{int}}$ & 0.0297 & 0.0407 & 0.0242 \\
\hline $\mathrm{R}_{1}[\mathrm{I}>2 \sigma(\mathrm{I})]$ & 0.0436 & 0.0426 & 0.0432 \\
\hline
\end{tabular}

Table S2. Hydrogen bond lengths and angles for $6 \mathbf{a}, \mathbf{6 b}$ I and $\mathbf{6 b}$ II at $100 \mathrm{~K}$.

\begin{tabular}{lllllll}
\hline Structure & $\mathrm{D}-\mathrm{H} \cdots \mathrm{A}$ & $\mathrm{D}-\mathrm{H} / \AA$ & $\mathrm{H} \cdots \mathrm{A} / \AA$ & $\mathrm{D} \cdots \mathrm{A} / \AA$ & $\mathrm{D}-\mathrm{H} \cdots \mathrm{A} /{ }^{\circ}$ & Symmetry codes \\
\hline 6a & $\mathrm{O} 1-\mathrm{H} 1 \cdots \mathrm{N} 5$ & $1.17(3)$ & $1.38(3)$ & $2.551(2)$ & $175(2)$ & \\
6b I & $\mathrm{O} 1-\mathrm{H} 1 \cdots \mathrm{O} 9$ & $0.98(3)$ & $1.52(3)$ & $2.495(2)$ & $174(3)$ & \\
& $\mathrm{O} 8-\mathrm{H} 8 \cdots \mathrm{O} 2$ & $1.03(3)$ & $1.59(3)$ & $2.613(2)$ & $171(2)$ & $x-1 / 2,-y+3 / 2, z-1 / 2$ \\
& $\mathrm{O} 16-\mathrm{H} 16 \cdots \mathrm{O} 10$ & $0.98(2)$ & $1.63(2)$ & $2.613(2)$ & $176(2)$ & $x+1 / 2,-y+1 / 2, z+1 / 2$ \\
& $\mathrm{~N} 20 \mathrm{~B}-\mathrm{H} 20 \mathrm{~B} \cdots \mathrm{O} 10$ & 0.88 & 1.90 & $2.769(5)$ & 169 & \\
6b II & $\mathrm{N} 25 \mathrm{~A}-\mathrm{H} 25 \mathrm{~A} \cdots \mathrm{O} 10$ & $0.97(3)$ & $1.78(3)$ & $2.748(6)$ & $176(2)$ & \\
& $\mathrm{O} 1-\mathrm{H} 1 \cdots \mathrm{O} 7$ & $0.95(2)$ & $1.65(2)$ & $2.601(1)$ & $175(2)$ & $x+1 / 2,-y+3 / 2, z+1 / 2$ \\
& $\mathrm{O} 16-\mathrm{H} 16 \cdots \mathrm{O} 9$ & $0.96(3)$ & $1.66(3)$ & $2.608(1)$ & $167(2)$ & $x-1 / 2,-y+1 / 2, z-1 / 2$ \\
& $\mathrm{O} 10-\mathrm{H} 10 \cdots \mathrm{O} 8$ & $0.98(3)$ & $1.52(3)$ & $2.501(1)$ & $178(3)$ & \\
& $\mathrm{N} 17 \mathrm{~A}-\mathrm{H} 17 \mathrm{~A} \cdots \mathrm{O} 7$ & 0.88 & 1.83 & $2.706(2)$ & 178 & \\
& $\mathrm{~N} 25 \mathrm{~B}-\mathrm{H} 25 \mathrm{~B} \cdots \mathrm{O} 7$ & 0.88 & 1.99 & $2.857(2)$ & 167 & \\
\hline
\end{tabular}




\section{NAM and BA}

The 1:1 co-crystals of nicotinamide and benzoic acid (polymorphs 7 I and 7 II) were made by subliming NAM $(0.070 \mathrm{~g}, 0.57 \mathrm{mmol})$ and BA $(70 \mathrm{~g}, 0.57 \mathrm{mmol})$ in a thin Schlenk heated at $100{ }^{\circ} \mathrm{C}$ for 6 hours under static vacuum (Figure S9). A 1:2 ratio could also be used. Grinding a 1:1 ratio of NAM and BA with the addition of $25 \mu 1$ of acetonitrile or water produced 7 II, while using $25 \mu 1$ of methanol does not yield either polymorph.

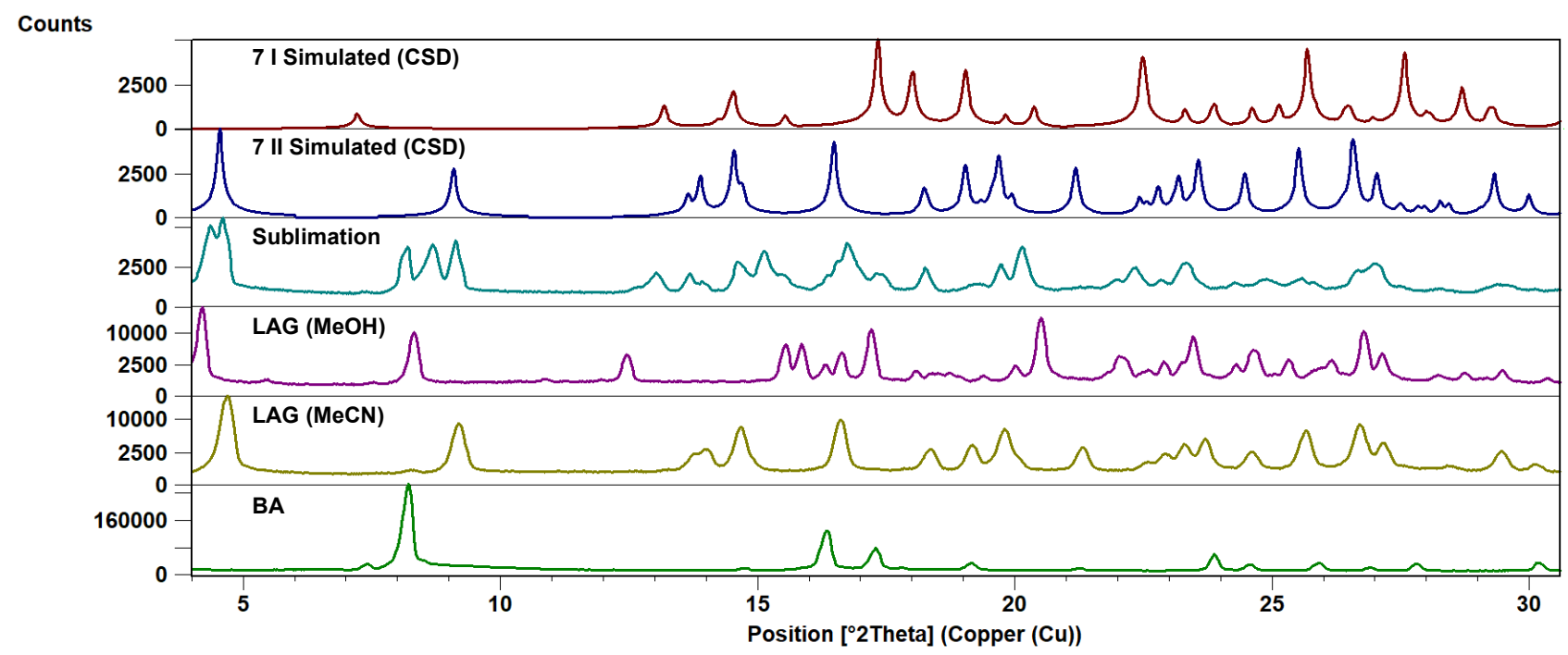

Figure S9. Comparison of the simulated powder patterns of 7 I and 7 II (obtained from the CSD) ${ }^{7}$ to the patterns of the products obtained from co-sublimation and co-grinding. Sublimation and $\mathrm{MeOH}$ LAG traces contain residual BA. The pattern of the product obtained from sublimation has peaks that can be ascribed to $\mathbf{7} \mathbf{I}$ and $\mathbf{7}$ II, while the pattern of the product obtained from LAG using acetonitrile matches 7 II.

\section{Co-crystallization when molecules have different sublimation temperatures}

\section{$M A$ and $B P Y$}

The 2:1 salt of maleic acid and 4,4'-bipyridine (8) was made by grinding MA (0.060 g, $0.51 \mathrm{mmol})$, BPY (0.040 g, $0.25 \mathrm{mmol}$ ), and $25 \mu \mathrm{l}$ THF together for 20 minutes in a ball mill (Figure S10). Methanol or water could also be used, or no solvent at all.

Single crystals of 8 could also be formed by sublimation of a 4:1 molar ratio of the starting materials. MA (0.035 g, $0.30 \mathrm{mmol})$ and BPY (0.012 g, $0.077 \mathrm{mmol})$ were added to a thin Schlenk tube and heated in a $100{ }^{\circ} \mathrm{C}$ oil bath for $4 \mathrm{~h}$ under static vacuum. 


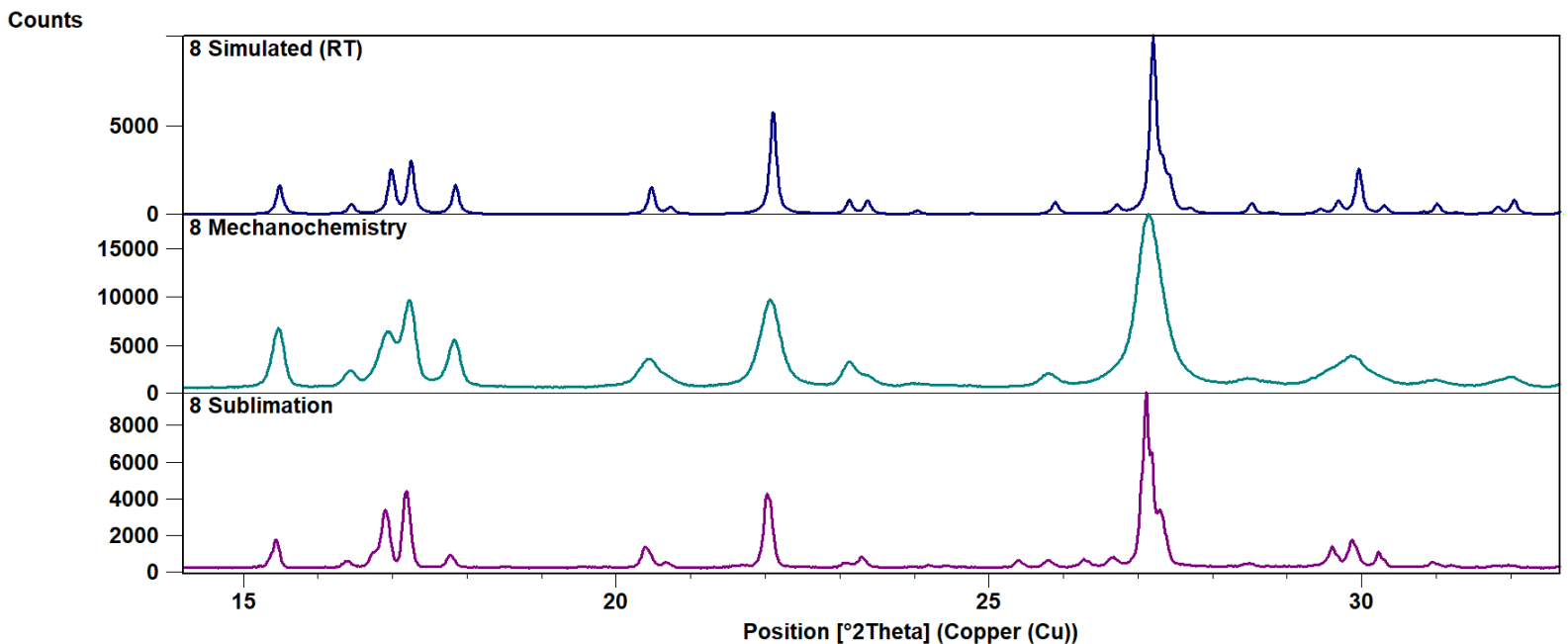

Figure S10. Comparison of the experimental powder patterns of 8 (obtained from LAG and cosublimation) to the pattern simulated from single-crystal data collected at room temperature.

Single-crystal data for $\mathbf{8}$ was collected to confirm its classification as a salt, along with FTIR data (Figure S12). Salt 8 crystallizes in the monoclinic spacegroup $C 2 / c$ with one hydrogen maleate ion and one half of a bipyridinium ion in the ASU. The monoanion, MA, forms a short intramolecular hydrogen bond between the carboxylic acid group and the carboxylate, with the latter also forming a charge-assisted hydrogen bond (CAHB) with BPY. Each end of the BPY cation has this interaction, so that acid-base-acid trimers are formed. The trimers pack together via various weak interactions to form the 3D structure (Figure S11). 

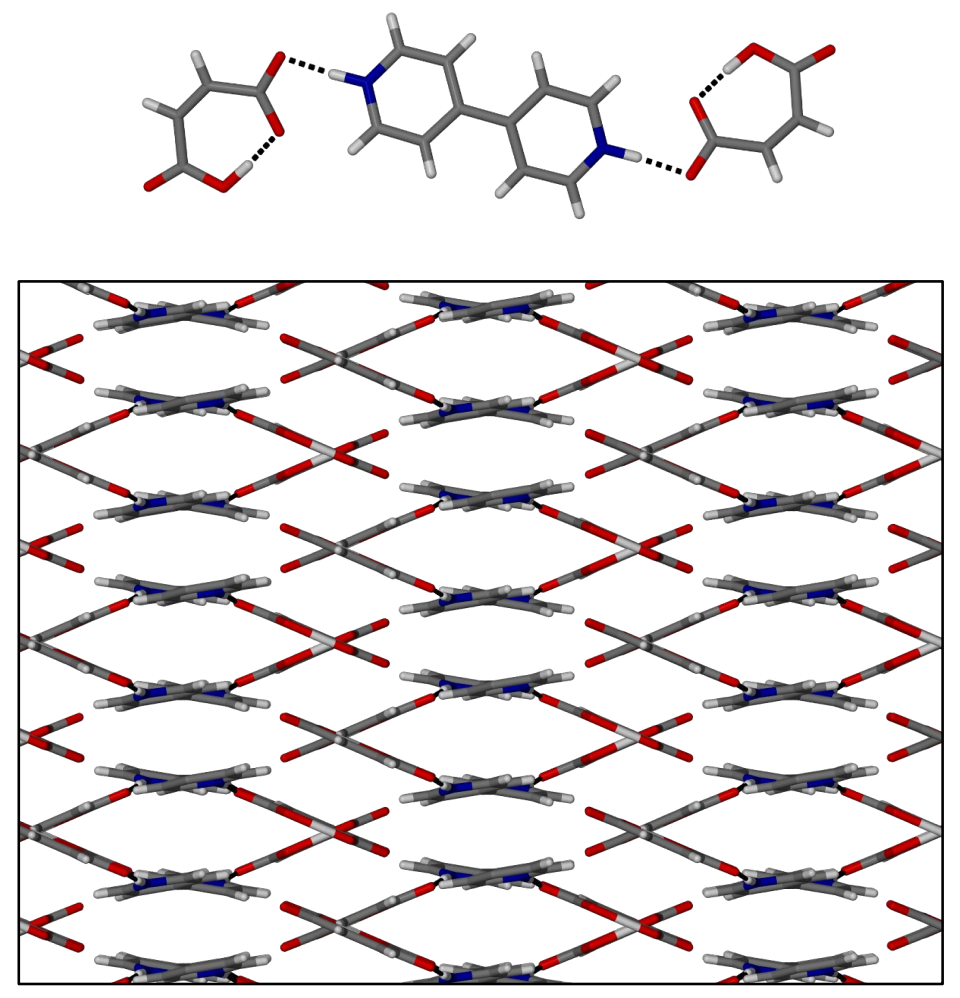

Figure S11. Hydrogen-bonded trimer of 8 (top) and the packing diagram for $\mathbf{8}$ viewed along [001] (bottom).

Table S3. Crystallographic data for the salt 8 .

\begin{tabular}{|l|c|}
\hline Structure & $\mathbf{8}$ \\
\hline Chemical formula & $\mathrm{C}_{18} \mathrm{H}_{16} \mathrm{~N}_{2} \mathrm{O}_{8}$ \\
Formula weight $/ \mathrm{g} \mathrm{mol}^{-1}$ & 388.33 \\
Crystal system & monoclinic \\
Space group & $C 2 / c$ \\
Temperature $/ \mathrm{K}$ & $298(2)$ \\
$a / \AA$ & $23.997(2)$ \\
$b / \AA$ & $6.8777(7)$ \\
$c / \AA$ & $11.446(1)$ \\
$\alpha /{ }^{\circ}$ & 90 \\
$\beta /{ }^{\circ}$ & $116.127(1)$ \\
$\gamma /{ }^{\circ}$ & 90 \\
Calc. density /g cm & \\
Volume / $\AA^{3}$ & 1.521 \\
$Z$ & $1696.1(3)$ \\
Independent reflections & 4 \\
$\mathrm{R}_{\text {int }}$ & 2101 \\
$\mathrm{R}_{1}[\mathrm{I}>2 \sigma(\mathrm{I})]$ & 0.0322 \\
\hline
\end{tabular}

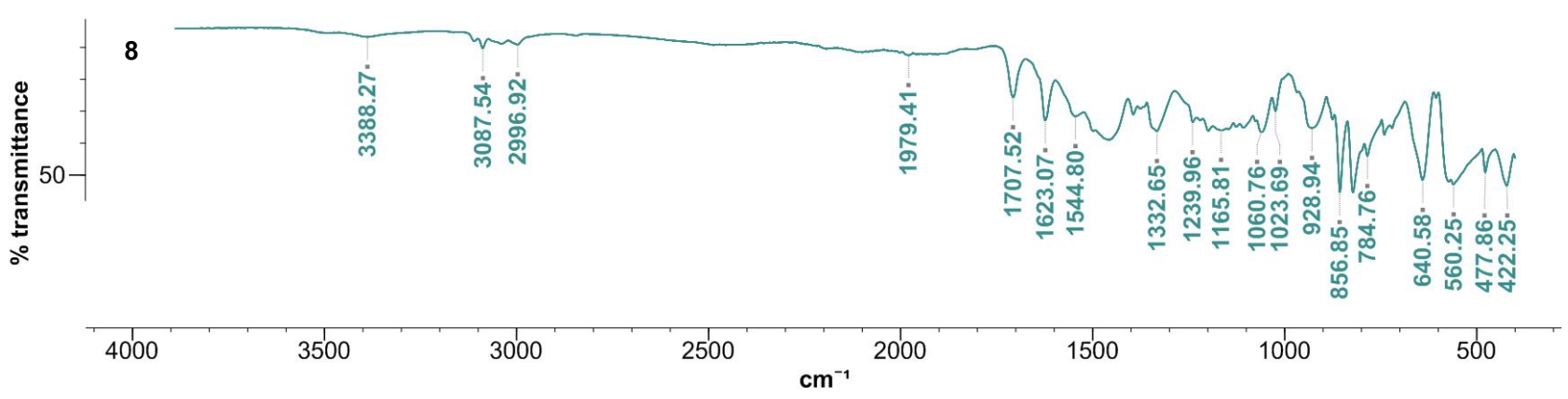

Figure S12. FTIR spectrum for salt 8 as obtained from LAG. The peaks at $1708 \mathrm{~cm}^{-1}$ and $1623 \mathrm{~cm}^{-1}$ indicate the presence of both carboxylic acid and carboxylate groups, which confirms that $\mathbf{8}$ is a salt. 


\section{FA and 23LUT}

The 2:1 co-crystal salt polymorphs of fumaric acid and 2,3-lutidine (6b I and $\mathbf{6 b}$ II) were made as a mixture by subliming FA (0.150 g, $1.29 \mathrm{mmol})$ while vaporizing 23LUT (147 $\mu 1,1.29 \mathrm{mmol})$ using in-house developed glassware (Figure S13). FA was heated at $200{ }^{\circ} \mathrm{C}$ and $23 \mathrm{LUT}$ at $40{ }^{\circ} \mathrm{C}$. A few single crystals of $\mathbf{6 b}$ I and $\mathbf{6 b}$ II formed; however, to ensure accuracy the experiment was carried out multiple times and crystals identified with PXRD (Figure S14) and unit cell determinations.

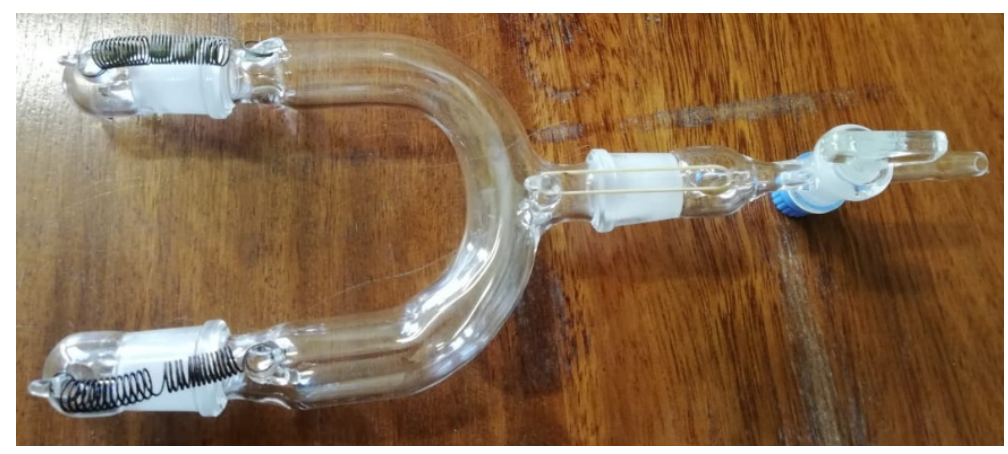

Figure S13. Apparatus for the sublimation of compounds at two different temperatures.

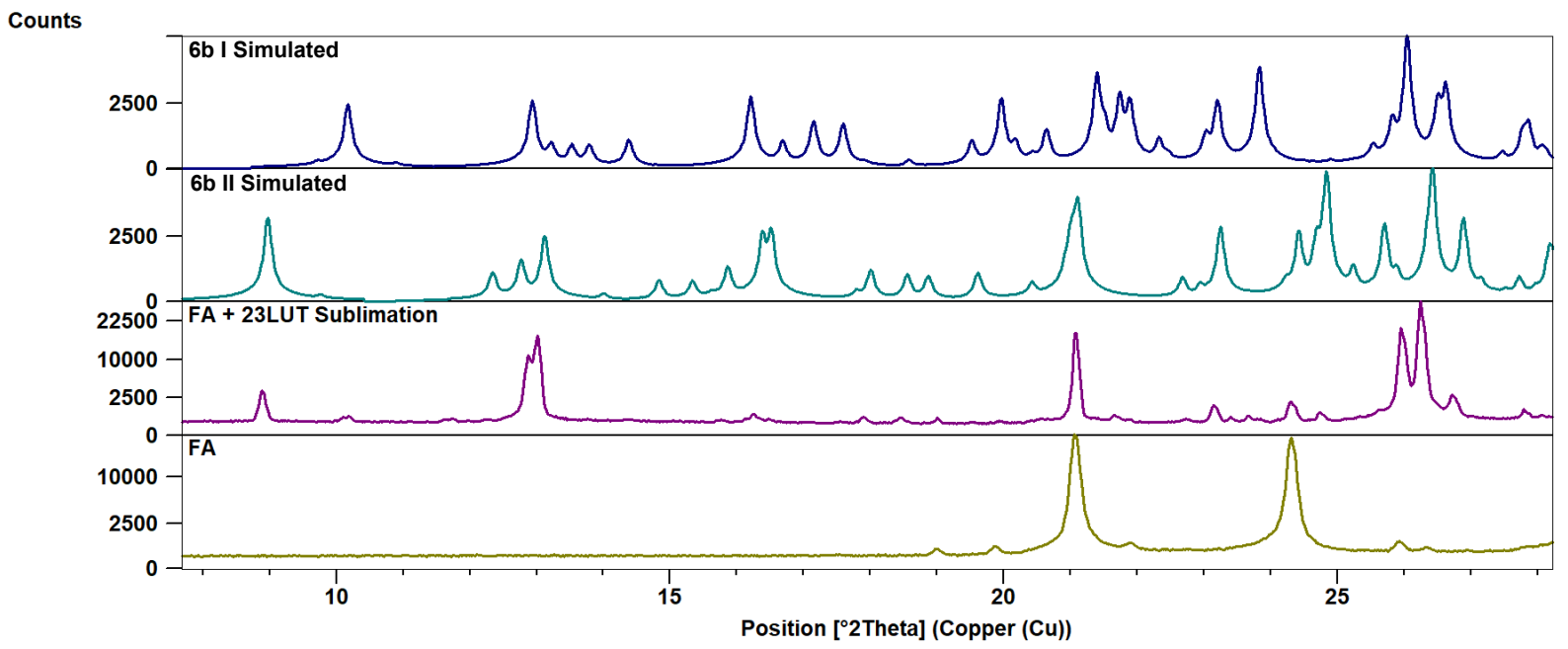

Figure S14. Comparison of the pattern obtained from sublimation using specialized glassware to the simulated powder patterns for $\mathbf{6 b}$ I and $\mathbf{6 b}$ II. The experimental trace contains both these polymorphs as well as some residual fumaric acid starting material. Poor pattern quality can be attributed to the small sample size and the fact that the sample consisted of single crystals, instead of powder (6b II converts to $6 \mathbf{b}$ I on grinding). 


\section{SA and PIP}

The 2:1 salt of succinic acid and piperazine (9a) was made by grinding SA $(0.074 \mathrm{~g}, 0.63 \mathrm{mmol})$ and PIP (0.027 g, $0.32 \mathrm{mmol}$ ) together for 20 minutes in a ball mill (neat or with the addition of methanol, THF or water). The 1:1 salt of succinic acid and piperazine $(\mathbf{9 b})$ was made by grinding SA (0.058 $\mathrm{g}$, $0.49 \mathrm{mmol})$ and PIP $(0.042 \mathrm{~g}, 0.49 \mathrm{mmol})$ together for 20 minutes in a ball mill (neat or with the addition of methanol, THF or water).

Co-crystal 9b could also be formed by sublimation of a 1:1 molar ratio of the starting materials. SA $(0.045 \mathrm{~g}, 0.38 \mathrm{mmol})$ and PIP $(0.033 \mathrm{~g}, 0.38 \mathrm{mmol})$ were added to a thin Schlenk tube and heated in a $140{ }^{\circ} \mathrm{C}$ oil bath for $2 \mathrm{~h}$ under static vacuum. A $2: 1$ or $4: 1$ ratio could also be used.

Crystals of 9a could also be obtained from solution crystallization. SA $(0.040 \mathrm{~g}, 0.34 \mathrm{mmol})$ and PIP (0.015 g, $0.17 \mathrm{mmol})$ were dissolved in $2 \mathrm{ml}$ ethanol and $0.5 \mathrm{ml}$ water at $70{ }^{\circ} \mathrm{C}$. The solution was left at room temperature and crystals formed after 24 hours. Crystals of $9 \mathbf{b}$ could similarly be obtained by dissolving SA (0.040 g, $0.34 \mathrm{mmol})$ and PIP $(0.029 \mathrm{~g}, 0.34 \mathrm{mmol})$ in $4 \mathrm{ml}$ dimethylformamide and $2 \mathrm{ml}$ water at $70{ }^{\circ} \mathrm{C}$. Crystals formed at room temperature after 24 hours.

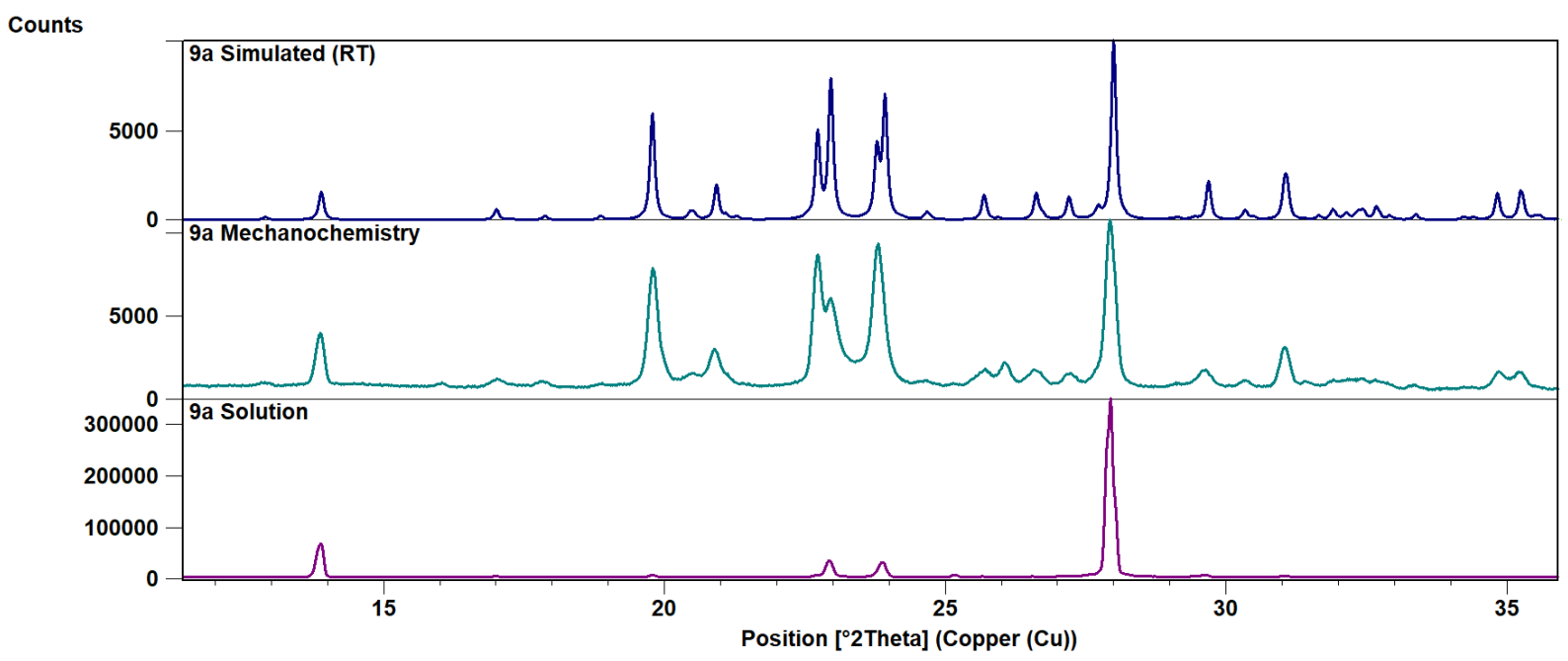

Figure S15. Comparison of the experimental powder patterns of 9a (obtained from grinding and solution crystallization) to the pattern simulated from single-crystal data collected at room temperature. 


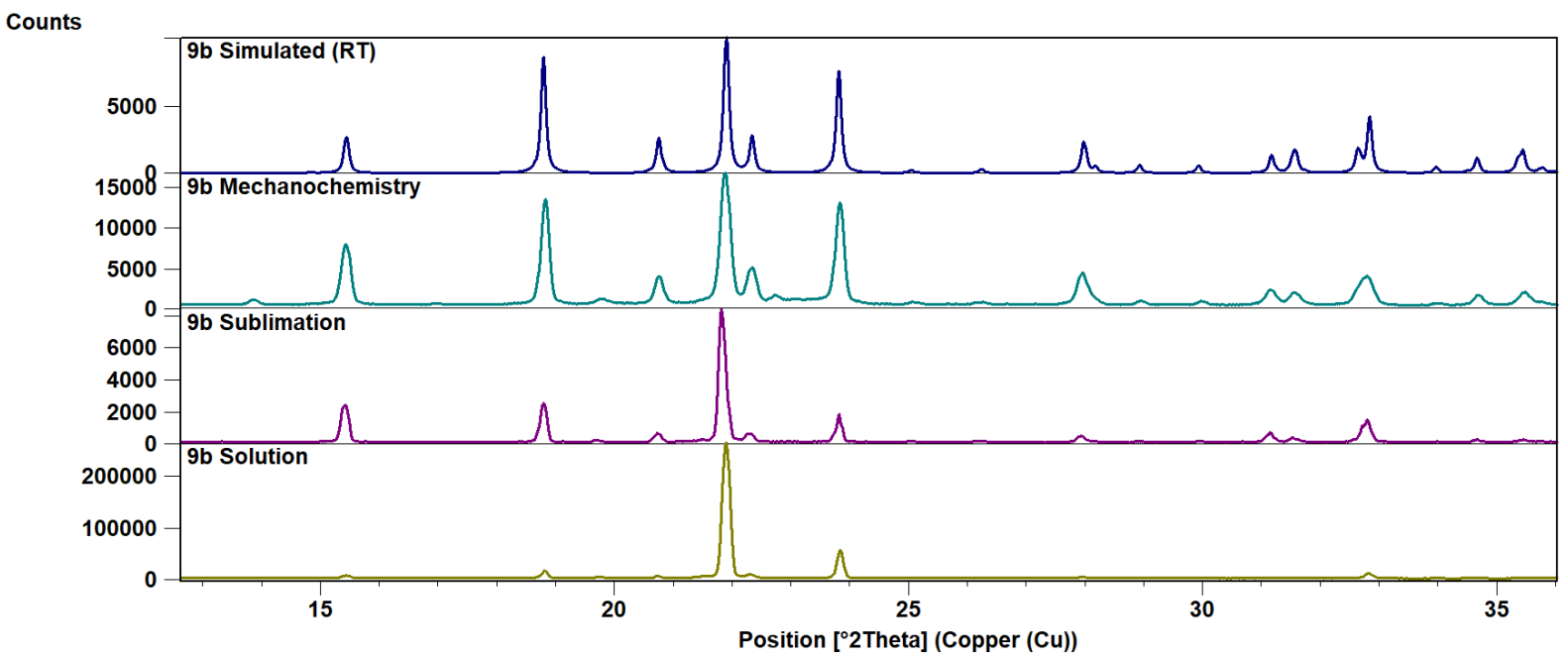

Figure S16. Comparison of the experimental powder patterns of $\mathbf{9 b}$ (obtained from grinding, cosublimation and solution crystallization) to the pattern simulated from single-crystal data collected at room temperature. The first peak in the trace obtained for mechanochemistry (at roughly $14^{\circ}$ ) is due to a small amount of 9a present in the sample.

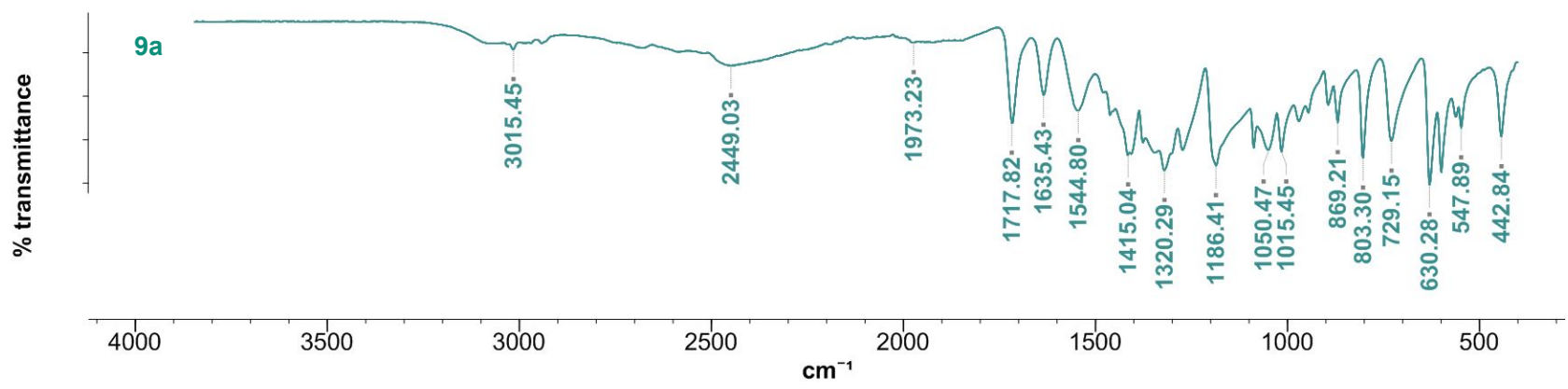

Figure S17. FTIR pattern for 9a. The peaks at $1718 \mathrm{~cm}^{-1}$ and $1635 \mathrm{~cm}^{-1}$ indicate the presence of both carboxylic acid and carboxylate groups (as can be seen in the crystal structure), which confirms that $9 \mathbf{a}$ is a salt.

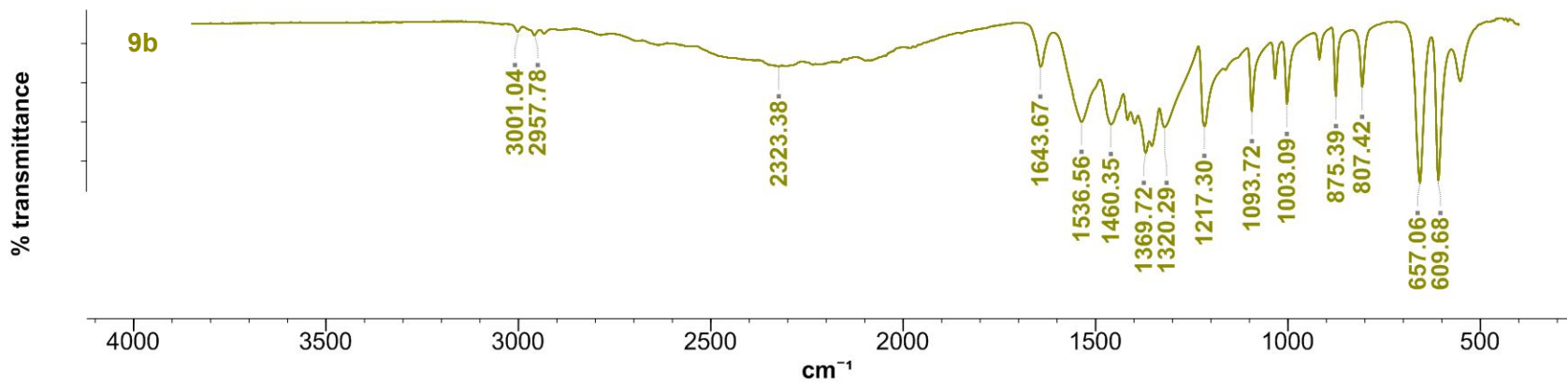

Figure S18. FTIR pattern for $9 b$. The peak at $1644 \mathrm{~cm}^{-1}$ indicate the presence of carboxylate groups (as can be seen in the crystal structure), which confirms that $\mathbf{9 b}$ is a salt. 
Salt 9a crystallizes in the triclinic spacegroup $P \overline{1}$, with two hydrogen succinate ions and two half PIP cations in the ASU. The SA anions hydrogen bond to each other forming zig-zag chains. Two such chains are held together by PIP cations linking to two carboxylate groups in each chain to form ribbons (Figure 8 in the paper). There are two types of ribbons that pack together to form the 3D structure - they differ with respect to the exact intermolecular distances.

Salt $9 \mathbf{b}$ crystallizes in the triclinic spacegroup $P \overline{1}$ with half a SA anion and half a PIP cation. Each succinate dianion forms four CAHBs to four different cations, and similarly, each PIP cation forms four CAHBs to four different anions so that hydrogen-bonded sheets are formed (Figure 8) that stack with bases overlapping acids, to give a layered structure.

Table S4. Crystallographic data for the salts $\mathbf{9 a}$ and $\mathbf{9 b}$.

\begin{tabular}{|l|c|c|}
\hline Structure & $\mathbf{9 a}$ & $\mathbf{9 b}$ \\
\hline Chemical formula & $\mathrm{C}_{24} \mathrm{H}_{44} \mathrm{~N}_{4} \mathrm{O}_{16}$ & $\mathrm{C}_{8} \mathrm{H}_{16} \mathrm{~N}_{2} \mathrm{O}_{4}$ \\
Formula weight $/ \mathrm{g} \mathrm{mol}^{-1}$ & 644.63 & 204.23 \\
Crystal system & triclinic & triclinic \\
Space group & $P \overline{\mathrm{I}}$ & $P \overline{\mathrm{l}}$ \\
Temperature $/ \mathrm{K}$ & $298(2)$ & $298(2)$ \\
$a / \AA$ & $6.5440(5)$ & $5.828(1)$ \\
$b / \AA$ & $8.6135(6)$ & $6.007(1)$ \\
$c / \AA$ & $12.7894(9)$ & $6.910(1)$ \\
$\alpha /{ }^{\circ}$ & $92.0020(1)$ & $94.993(2)$ \\
$\beta /{ }^{\circ}$ & $94.0400(1)$ & $99.339(2)$ \\
$\gamma /{ }^{\circ}$ & $101.9450(1)$ & $93.730(2)$ \\
Calc. density $/ \mathrm{g} \mathrm{cm}{ }^{-3}$ & 1.523 & 1.431 \\
Volume $/ \AA^{3}$ & $702.63(9)$ & $237.05(8)$ \\
$Z$ & 1 & 1 \\
Independent reflections & 3480 & 1178 \\
$\mathrm{R}_{\text {int }}$ & 0.0234 & 0.0234 \\
$\mathrm{R}_{1}[\mathrm{I}>2 \sigma(\mathrm{I})]$ & 0.0414 & 0.0425 \\
\hline
\end{tabular}


Table S5. Hydrogen bond lengths and angles for $\mathbf{9 a}$ and $\mathbf{9 b}$ at room temperature.

\begin{tabular}{lllllll}
\hline Structure & $\mathrm{D}-\mathrm{H} \cdots \mathrm{A}$ & $\mathrm{D}-\mathrm{H} / \AA$ & $\mathrm{H} \cdots \mathrm{A} / \AA$ & $\mathrm{D} \cdots \mathrm{A} / \AA$ & $\mathrm{D}-\mathrm{H} \cdots \mathrm{A} /{ }^{\circ}$ & Symmetry codes \\
\hline 9a & $\mathrm{O} 7-\mathrm{H} 7 \cdots \mathrm{O} 2$ & $0.94(3)$ & $1.61(3)$ & $2.541(2)$ & $171(2)$ & $x+1, y, z$ \\
& $\mathrm{O} 15-\mathrm{H} 15 \cdots \mathrm{O} 10$ & $0.94(3)$ & $1.60(3)$ & $2.535(2)$ & $172(2)$ & $x+1, y, z$ \\
& $\mathrm{~N} 17-\mathrm{H} 17 \mathrm{~A} \cdots \mathrm{O} 9$ & $0.93(2)$ & $2.12(2)$ & $2.907(2)$ & $142(2)$ & $-x+1,-y+2,-z+1$ \\
& $\mathrm{~N} 17-\mathrm{H} 17 \mathrm{~B} \cdots \mathrm{O} 9$ & $0.95(2)$ & $1.79(2)$ & $2.722(2)$ & $168(2)$ & \\
& $\mathrm{N} 20-\mathrm{H} 20 \mathrm{~A} \cdots \mathrm{O} 1$ & $0.90(2)$ & $2.06(2)$ & $2.852(2)$ & $148(2)$ & $-x+1,-y+1,-z$ \\
& $\mathrm{~N} 20-\mathrm{H} 20 \mathrm{~B} \cdots \mathrm{O} 1$ & $0.94(2)$ & $1.83(2)$ & $2.749(2)$ & $165(2)$ & \\
9b & $\mathrm{N} 5-\mathrm{H} 5 \mathrm{~A} \cdots \mathrm{O} 1$ & $0.93(2)$ & $1.80(2)$ & $2.730(1)$ & $172(2)$ & $x, y+1, z$ \\
& $\mathrm{~N} 5-\mathrm{H} 5 \mathrm{~B} \cdots \mathrm{O} 1$ & $0.96(2)$ & $1.73(2)$ & $2.659(2)$ & $165(2)$ & \\
\hline
\end{tabular}

\section{Co-crystallization when coformers can isomerize}

\section{MA and PYR}

The 1:1 salt of maleic acid and pyridine (10) was made by grinding MA (0.048 $\mathrm{g}, 0.41 \mathrm{mmol})$ and pyridine $(34 \mu 1,0.41 \mathrm{mmol})$ together for 20 minutes in a ball mill (Figure S19). A 1:2 molar ratio could also be used.

Salt 10 could also be formed by sublimation of a 1:1 molar ratio of the starting materials. MA $(0.120 \mathrm{~g}, 1.0 \mathrm{mmol})$ and PYR $(83 \mu 1,1.0 \mathrm{mmol})$ were added to a large Schlenk tube and heated in a $120{ }^{\circ} \mathrm{C}$ oil bath for $5 \mathrm{~h}$ under static vacuum. A lower temperature of $100^{\circ} \mathrm{C}$ could also be used. Single crystals were obtained that were used to determine the crystal structure by single-crystal diffraction. Crystals of 11a and 11b formed alongside crystals of 10 on the coldfinger.

Salt 10 could also be formed by dissolving MA $(150 \mathrm{mg})$ in PYR $(5 \mathrm{ml})$ at $50{ }^{\circ} \mathrm{C}$. The vial was capped and placed in the refrigerator at $4{ }^{\circ} \mathrm{C}$. Crystals formed within 24 hours.

Crystals of the zwitterion could be formed by dissolving MA $(0.040 \mathrm{~g}, 0.34 \mathrm{mmol})$ and PYR $(28 \mu 1,0.34 \mathrm{mmol})$ in $2 \mathrm{ml}$ methanol at $60{ }^{\circ} \mathrm{C}$. Vials were capped and left undisturbed until crystals formed a few days later. Other solvents such as ethanol, acetone or THF could also be used, and MA could also be replaced with FA. 


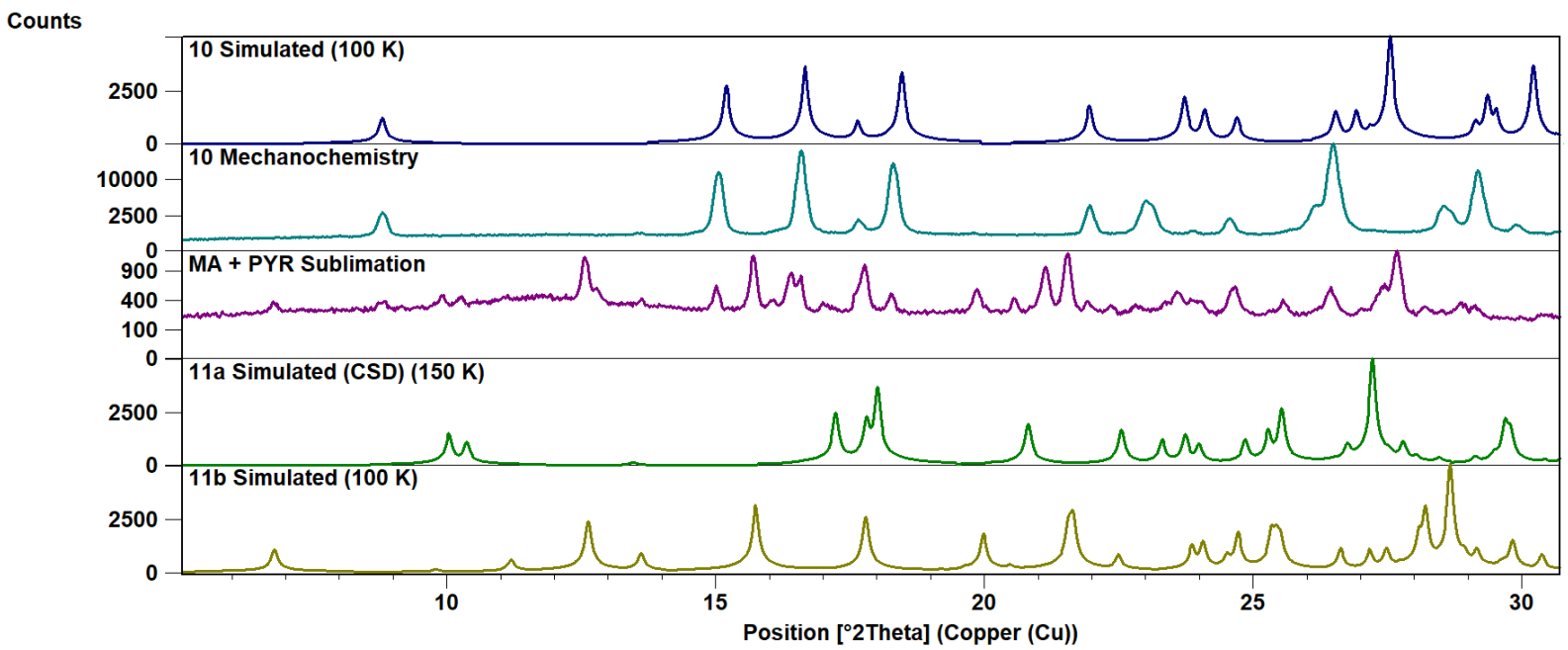

Figure S19. Comparison of the experimental pattern for $\mathbf{1 0}$ obtained from grinding to the pattern simulated from single crystal data. The experimental pattern obtained from sublimation of MA and PYR shows that 10, 11a, and 11b is formed simultaneously.

Salt 10 crystallizes in the triclinic spacegroup, $P 1$ (Table S6), with one pyridinium ion and one intramolecularly hydrogen-bonded hydrogen succinate in the asymmetric unit. The cation interacts with the anion via a charge-assisted hydrogen bond and these dimers stack via $\pi-\pi$ interactions. The structure has been checked for higher symmetry, and the assigned space group is correct.

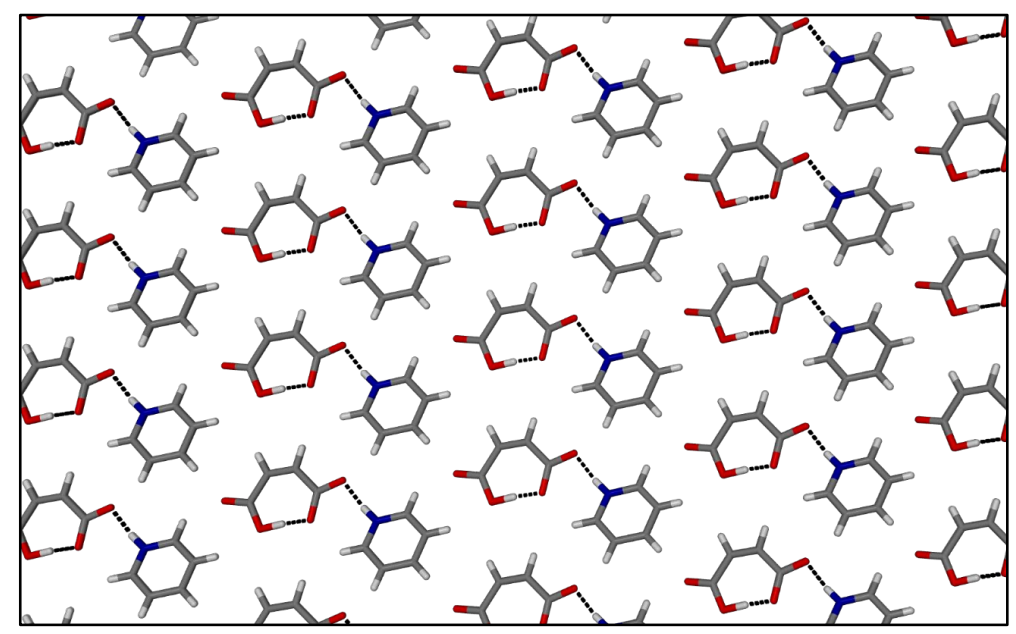

Figure S20. Packing diagram for salt 10 viewed along [100].

\section{FA and PYR}

The 1:1 co-crystal salt, 11b, was made by grinding FA $(0.043 \mathrm{~g}, 0.37 \mathrm{mmol})$ and PYR $(60 \mu 1$, $0.74 \mathrm{mmol}$ ) together for 20 minutes in a ball mill. An unknown product was obtained by grinding FA $(0.060 \mathrm{~g}, 0.52 \mathrm{mmol})$ and PYR $(42 \mu 1,0.52 \mathrm{mmol})$ in a 1:1 molar ratio. 
Single crystals of 11b (as well as a powder of the unknown product) could also be formed by sublimation of FA and PYR. FA $(0.12 \mathrm{~g}, 1.0 \mathrm{mmol})$ and PYR $(83 \mu 1,1.0 \mathrm{mmol})$ were added to a large Schlenk tube and heated in a $170{ }^{\circ} \mathrm{C}$ oil bath for 15 hours under static vacuum.

Crystals of 11a and $\mathbf{1 1 b}$ could also be formed by dissolving FA $(150 \mathrm{mg})$ in PYR $(5 \mathrm{ml})$ at $50{ }^{\circ} \mathrm{C}$. The vial was capped and placed in the refrigerator at $4{ }^{\circ} \mathrm{C}$. Crystals formed within 24 hours.

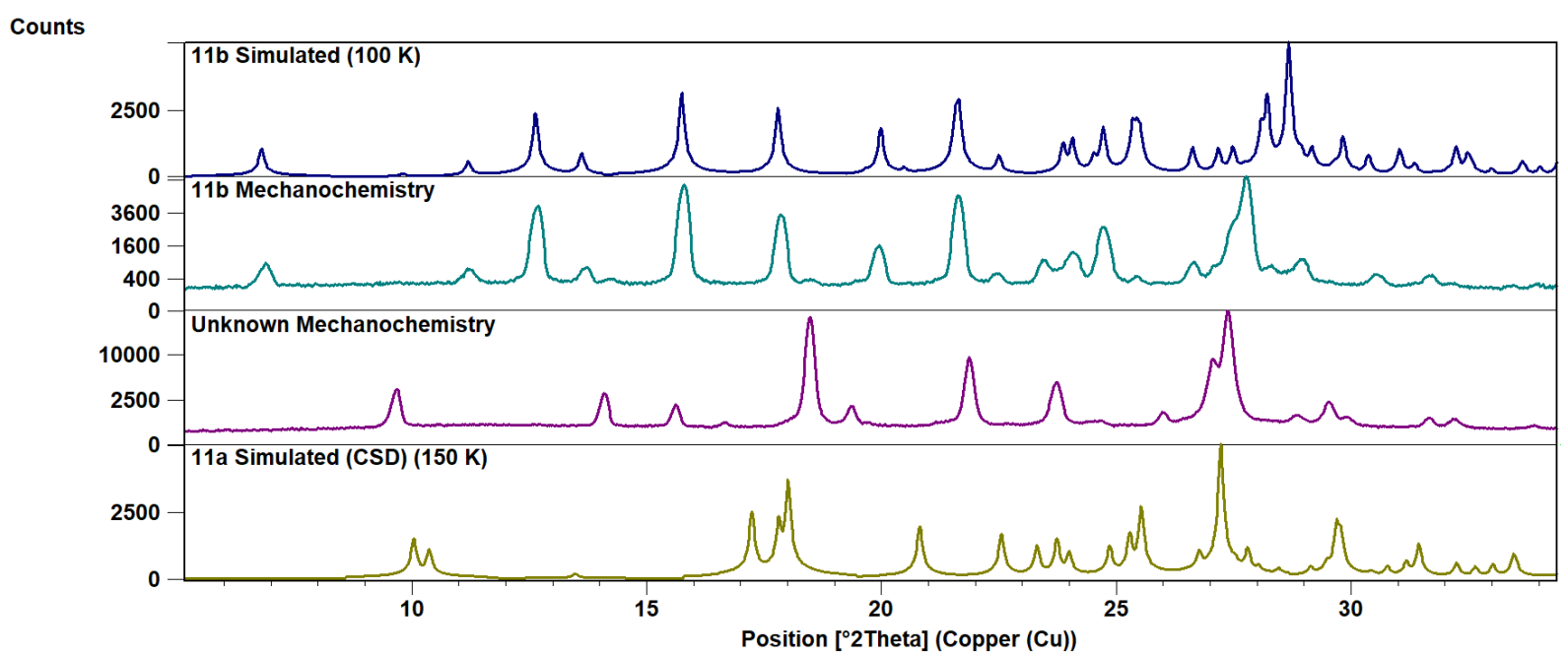

Figure S21. Comparison of the experimental pattern for $\mathbf{1 1 b}$ obtained from grinding to the pattern simulated from single crystal data. An unknown pattern was also obtained mechanochemically, which does not match either 11a or $\mathbf{1 1 b}$.

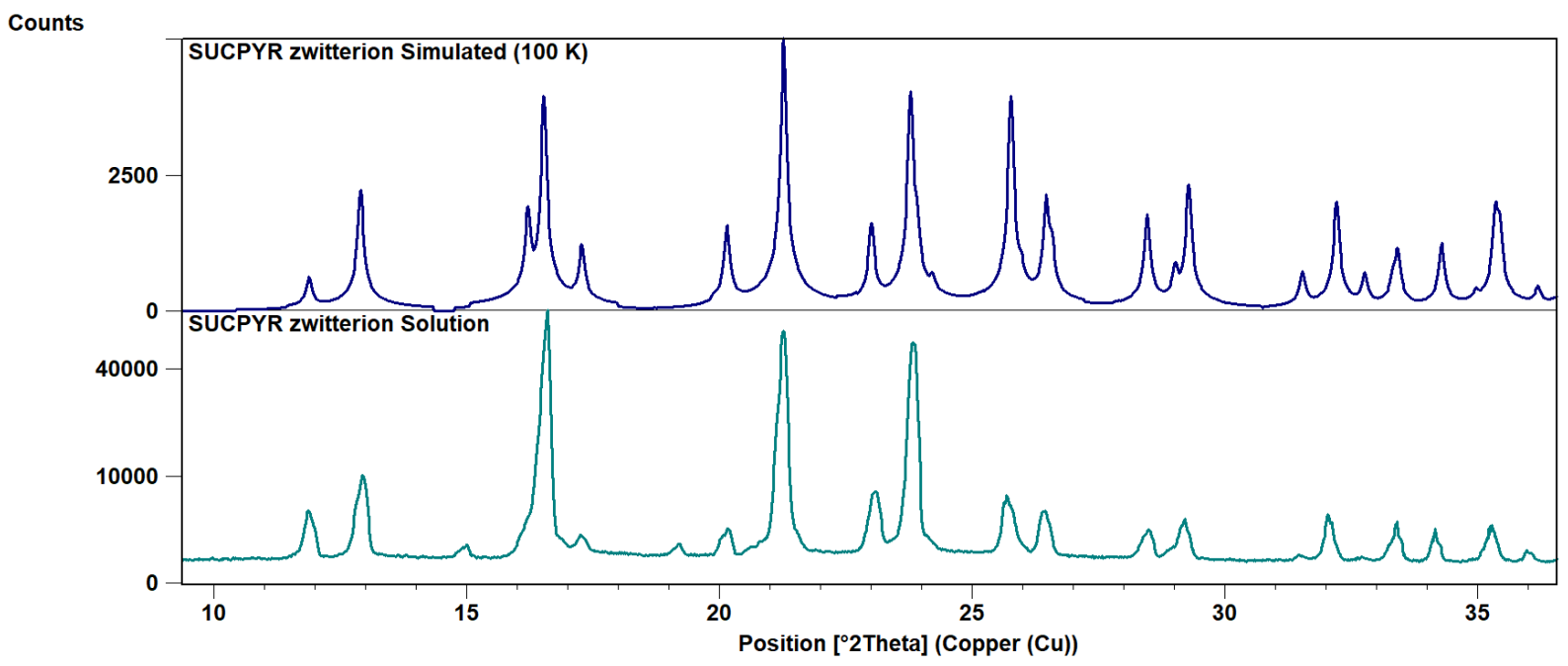

Figure S22. Comparison of the experimental pattern for the SUCPYR zwitterion obtained from solution crystallization to the pattern simulated from single crystal data.

The co-crystal salt $\mathbf{1 1 b}$ crystallizes in the triclinic spacegroup, $P \overline{1}$ (Table S6), with one pyridinium ion, one half of a fumaric acid molecule and one half of a fumarate anion in the asymmetric unit. FA and $\mathrm{FA}^{2-}$ form hydrogen-bonded zig-zag chains, with each carboxylate functional group forming an 
additional charge-assisted hydrogen bond with a pyridinium cation. These chains stack via $\pi-\pi$ interactions.

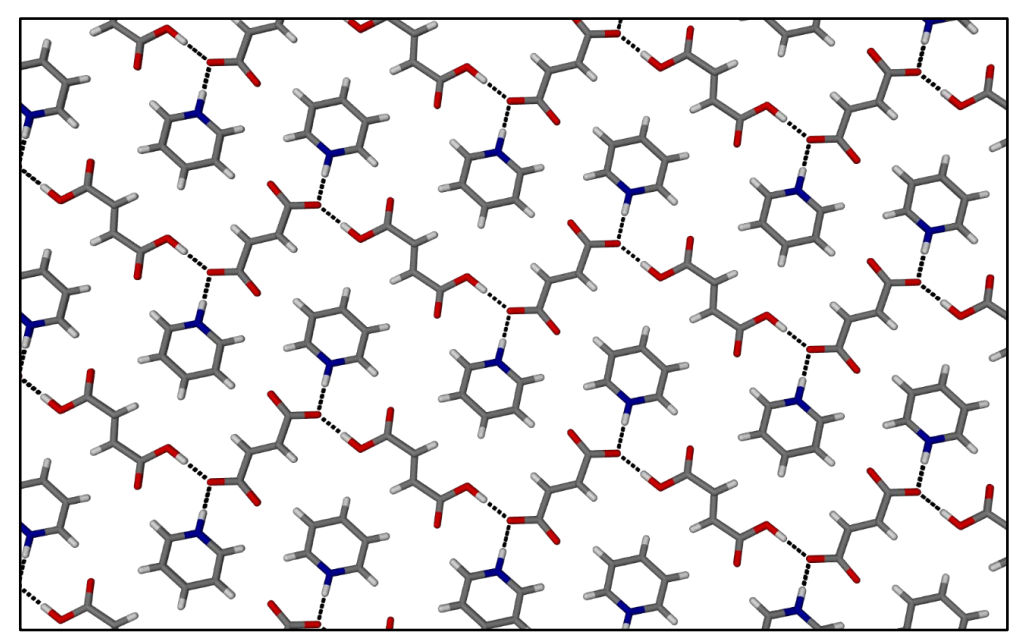

Figure S23. Packing diagram for 11b viewed along [100].

Table S6. Crystallographic data for $\mathbf{1 0}, \mathbf{1 1 b}$ and $\mathbf{1 2 b}$.

\begin{tabular}{|l|c|c|c|}
\hline Structure & $\mathbf{1 0}$ & $\mathbf{1 1 b}$ & $\mathbf{1 2 b}$ \\
\hline Chemical formula & $\mathrm{C}_{9} \mathrm{H}_{9} \mathrm{NO}_{4}$ & $\mathrm{C}_{18} \mathrm{H}_{18} \mathrm{~N}_{2} \mathrm{O}_{8}$ & $\mathrm{C}_{20} \mathrm{H}_{22} \mathrm{~N}_{2} \mathrm{O}_{8}$ \\
Formula weight $/ \mathrm{g} \mathrm{mol}^{-1}$ & 195.17 & 390.34 & 418.39 \\
Crystal system & triclinic & triclinic & triclinic \\
Space group & $P 1$ & $P \overline{\mathrm{I}}$ & $P \overline{\mathrm{l}}$ \\
Temperature $/ \mathrm{K}$ & $100(2)$ & $100(2)$ & $100(2)$ \\
$a / \AA$ & $3.8035(2)$ & $3.7446(5)$ & $3.8504(6)$ \\
$b / \AA$ & $5.9008(3)$ & $9.2066(1)$ & $8.9317(1)$ \\
$c / \AA$ & $10.2405(5)$ & $13.1148(2)$ & $14.638(2)$ \\
$\alpha /{ }^{\circ}$ & $82.498(1)$ & $96.994(3)$ & $80.664(3)$ \\
$\beta /{ }^{\circ}$ & $81.078(1)$ & $91.568(2)$ & $82.913(3)$ \\
$\gamma /{ }^{\circ}$ & $84.150(1)$ & $98.886(2)$ & $80.197(3)$ \\
Calc. density $/ \mathrm{g} \mathrm{cm}{ }^{-3}$ & 1.445 & 1.464 & 1.426 \\
Volume $/ \AA^{3}$ & $224.33(2)$ & $442.89(6)$ & $487.12(1)$ \\
$Z$ & 1 & 1 & 1 \\
Independent reflections & 2232 & 1562 & 1742 \\
$\mathrm{R}_{\text {int }}$ & 0.0141 & 0.0185 & 0.0236 \\
$\mathrm{R}_{1}[\mathrm{I}>2 \sigma(\mathrm{I})]$ & 0.0256 & 0.0285 & 0.0378 \\
\hline
\end{tabular}




\section{MA and $3 P I C$}

Single crystals of the 1:1 co-crystal salt of maleic acid and 3-picoline (12b) were obtained by cosubliming MA $(0.045 \mathrm{~g}, 0.39 \mathrm{mmol})$ and 3PIC (38 $\mu 1,0.39 \mathrm{mmol})$ in a large Schlenk tube heated to $130{ }^{\circ} \mathrm{C}$ for 5 hours under static vacuum.

Grinding MA (0.045 g, $0.39 \mathrm{mmol})$ and 3PIC (38 $\mu 1,0.39 \mathrm{mmol})$ together for 30 minutes in a ball mill (neat or with THF) lead to the formation of an unknown product. Dissolving MA (0.089 g, $0.77 \mathrm{mmol}$ ) and 3PIC (75 $\mu 1,0.77 \mathrm{mmol})$ in $5 \mathrm{ml}$ acetone or methanol (or 3PIC) at $60{ }^{\circ} \mathrm{C}$ lead to the formation of another unknown powder.

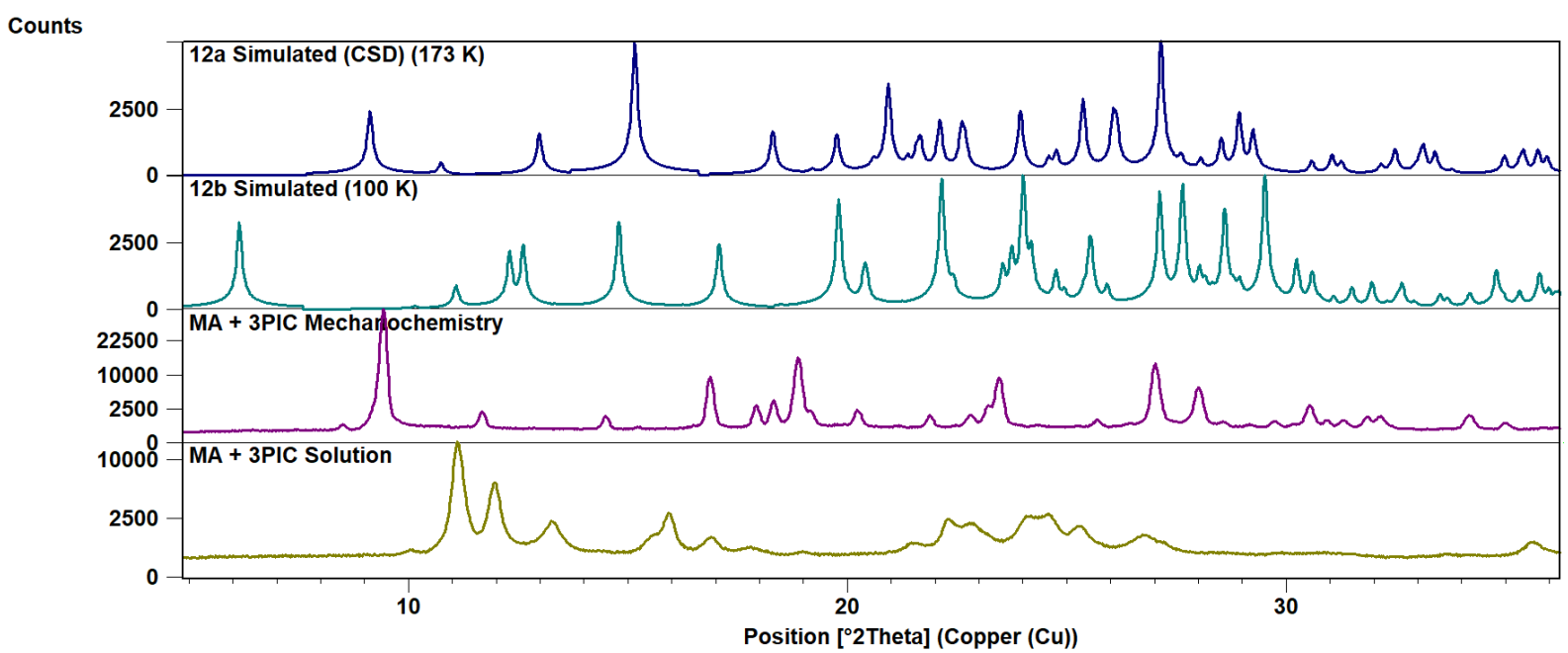

Figure S24. Simulated powder patterns for 12a and 12b compared to the unknown patterns obtained from mechanochemistry and solution crystallization.

The new co-crystal salt, $\mathbf{1 2 b}$, crystallizes in the triclinic spacegroup P $\overline{1}$ with one 3-methylpyridinium cation, one half fumaric acid molecule and one half of a fumarate anion. Similar to 11b, FA and FA ${ }^{2-}$ form hydrogen-bonded chains, with each carboxylate functional group forming an additional chargeassisted hydrogen bond with the cation. These chains stack via $\pi-\pi$ interactions. 


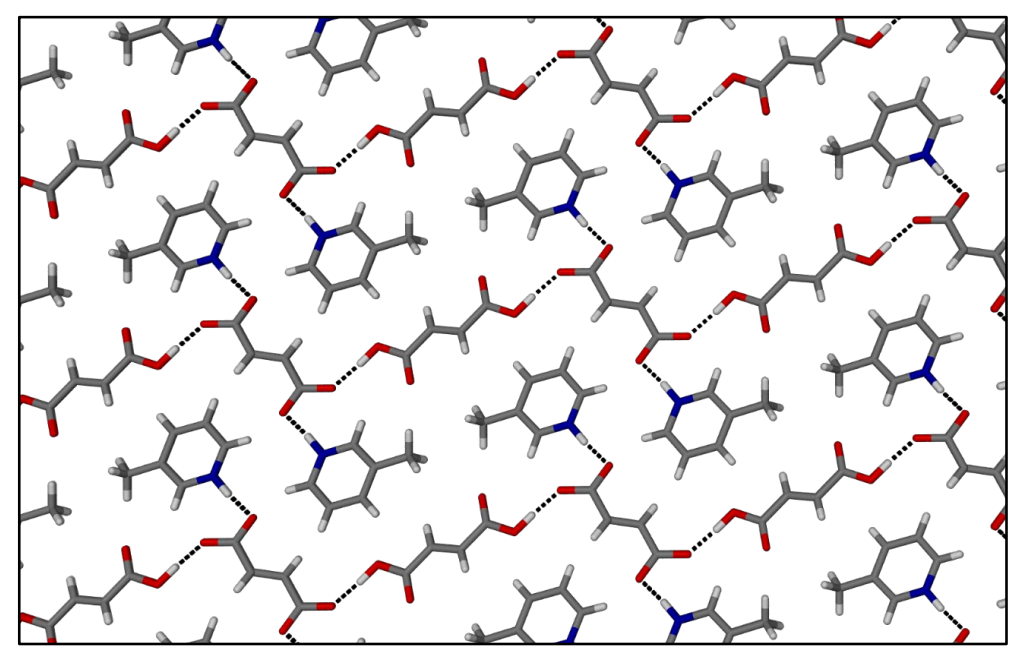

Figure S25. Packing diagram for 12b viewed along [100].

\section{Salts by co-sublimation}

\section{$N A$ and $O A$}

The 1:1 salt of nicotinic acid and oxalic acid (13) was made by adding NA (0.035 g, $0.28 \mathrm{mmol})$ and OA $(0.036 \mathrm{~g}, 0.28 \mathrm{mmol})$ to a thin Schlenk tube and placing it under static vacuum. The mixture was heated at $120{ }^{\circ} \mathrm{C}$ for 7 hours after which all starting materials had converted to the salt.

\section{Co-crystallization using heat-sensitive molecules}

\section{PYG and HMT}

The 1:1 co-crystal of pyrogallol and hexamethylenetetramine (14) was made by grinding PYG $(0.047 \mathrm{~g}, 0.37 \mathrm{mmol})$, HMT $(0.052 \mathrm{~g}, 0.37 \mathrm{mmol})$, and methanol $(25 \mu \mathrm{l})$ together for 20 minutes in a ball mill (Figure S26).

Co-crystal 14 could also be formed by sublimation of a 1:1 molar ratio of the starting materials. PYG (0.070 g, $0.56 \mathrm{mmol})$ and HMT (0.078 g, $0.56 \mathrm{mmol})$ were added to a thin Schlenk tube and heated in a $110{ }^{\circ} \mathrm{C}$ or $120^{\circ} \mathrm{C}$ oil bath for $6 \mathrm{~h}$ under static vacuum. HMT crystals formed higher up in the tube as well, in a separate band. 


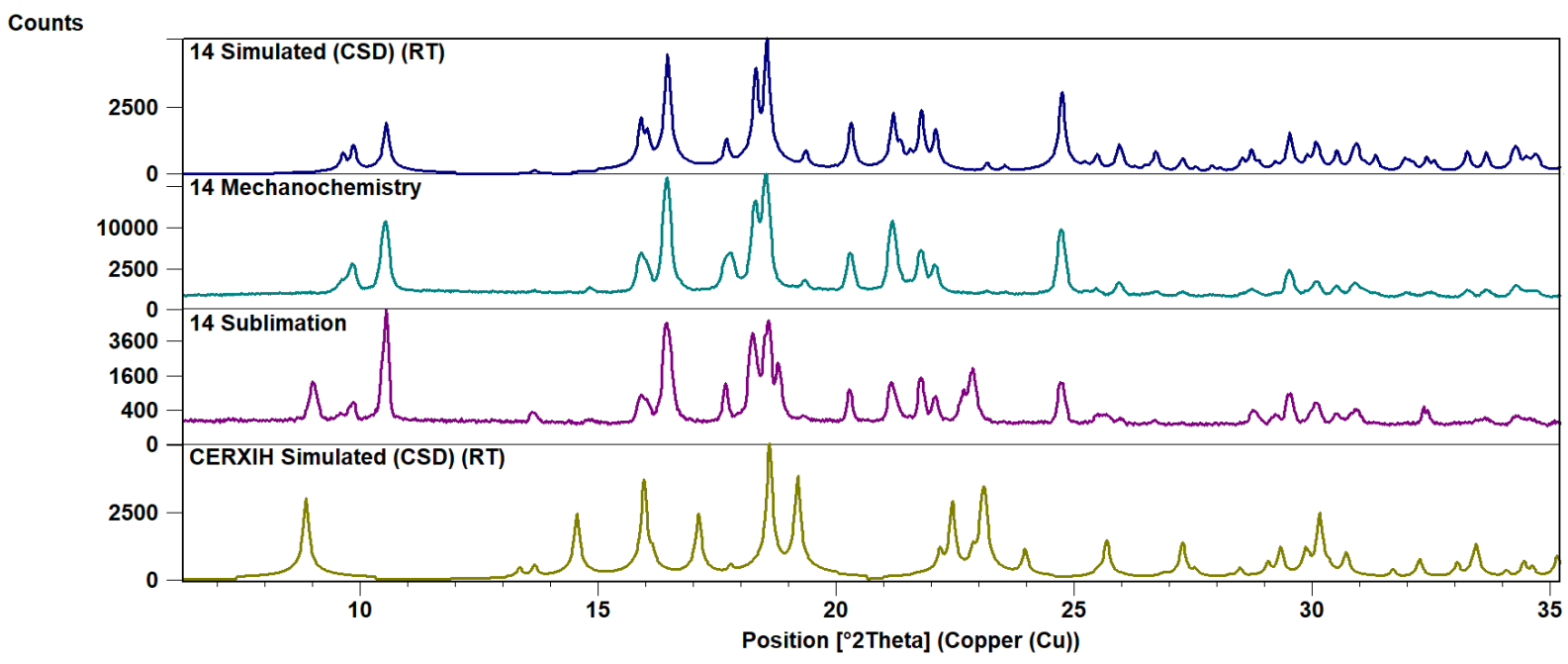

Figure S26. Comparison of the experimental powder patterns of $\mathbf{1 4}$ (obtained from LAG and cosublimation) to the pattern simulated form single-crystal data obtained from the CSD (refcode BINDIL) ${ }^{9}$. The material obtained from co-sublimation also contains some of the dihydroxybenzeneHMT co-crystal (CSD refcode CERXIH).

\section{GA and 4PP}

The 1:1 salt of gallic acid and 4-phenylpyridine (15) was made by grinding GA (0.055 g, $0.32 \mathrm{mmol})$ and 4PP (0.045 g, $0.32 \mathrm{mmol})$ together for 20 minutes in a ball mill (25 $\mu 1$ of methanol, THF or water could also be added). When subliming these starting materials, GA decarboxylated to form pyrogallol, which co-crystallized with 4PP to give a new co-crystal (16). Specifically, GA (0.055 g, $0.32 \mathrm{mmol})$ and $4 \mathrm{PP}(0.045 \mathrm{~g}, 0.32 \mathrm{mmol})$ were added to a thin Schlenk tube and heated under vacuum at $190^{\circ} \mathrm{C}$ for 2 hours.

Co-crystal 16 crystallizes in the monoclinic spacegroup $P 2_{1} / n$ with two molecules PYG and two molecules 4PP in the ASU. The 4PP molecules are disordered over two positions in an approximately 60:40 ratio such that the nitrogen atom can be at either end of the molecule (Figure S27). The 4PP molecules hydrogen bond to pyrogallol forming curved chains which pack together via PYG-PYG hydrogen bonds and $\pi-\pi$ interactions to give the $3 \mathrm{D}$ structure.

However, each disordered 4PP molecule naturally only forms a hydrogen bond at one end (via the nitrogen atom). At the other end there is a phenyl group which does not hydrogen bond to pyrogallol. This means that the hydroxyl hydrogen atom of pyrogallol (that is involved in hydrogen bonding to the other disordered part of 4PP) needs to occupy another position when the phenyl group is pointing towards it. The positions of these partially occupied hydrogen atoms could not be determined. Some additional constraints were also needed to model the disorder in the structure. 


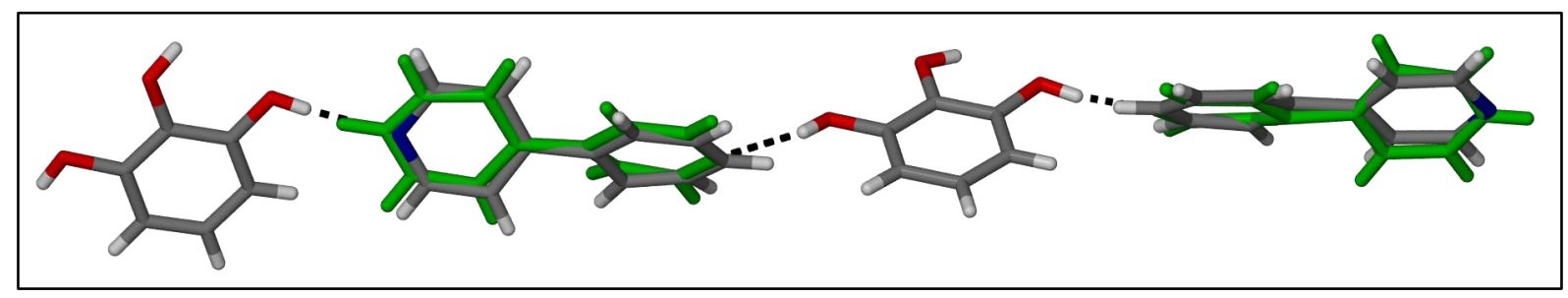

Figure S27. Asymmetric unit for the co-crystal between pyrogallol and 4-phenylpyridine (16). 4PP is disordered over two positions (50:50 occupancy) - one of the positions is indicated in green.

Table S7. Crystallographic data for co-crystal 16.

\begin{tabular}{|l|c|}
\hline Structure & $\mathbf{1 6}$ \\
\hline Chemical formula & $\mathrm{C}_{34} \mathrm{H}_{30} \mathrm{~N}_{2} \mathrm{O}_{6}$ \\
Formula weight $/ \mathrm{g} \mathrm{mol}^{-1}$ & 562.60 \\
Crystal system & monoclinic \\
Space group & $P 2_{1} / n$ \\
Temperature $/ \mathrm{K}$ & $298(2)$ \\
$a / \AA$ & $13.1236(6)$ \\
$b / \AA$ & $15.0024(7)$ \\
$c / \AA$ & $14.4778(7)$ \\
$\alpha /{ }^{\circ}$ & 90 \\
$\beta /{ }^{\circ}$ & $106.4680(1)$ \\
$\gamma /{ }^{\circ}$ & 90 \\
Calc. density $/ \mathrm{g} \mathrm{cm}{ }^{-3}$ & 1.362 \\
Volume $/ \AA^{3}$ & $2733.5(2)$ \\
$Z$ & 4 \\
Independent reflections & 5221 \\
$\mathrm{R}_{\text {int }}$ & 0.0490 \\
$\mathrm{R}_{1}[\mathrm{I}>2 \sigma(\mathrm{I})]$ & 0.0610 \\
\hline
\end{tabular}




\section{References}

[1] Lu, E.; Rodríguez-Hornedo, N.; Suryanarayanan, R. CrystEngComm 2008, 10 (6), 665-668.

[2] Trask, A. V.; Motherwell, W. D. S.; Jones, W. Cryst. Growth Des. 2005, 5 (3), 1013-1021.

[3] Childs, S. L.; Stahly, G. P.; Park, A. Mol. Pharm. 2007, 4 (3), 323-338.

[4] Trask, A.; Motherwell, W.; Jones, W. Int. J. Pharm. 2006, 320 (1-2), 114-123.

[5] Fischer, F.; Lubjuhn, D.; Greiser, S.; Rademann, K.; Emmerling, F. Cryst. Growth Des. 2016, $16(10), 5843-5851$.

[6] Haynes, D. A.; Jones, W.; Motherwell, W. D. S. CrystEngComm 2006, 8 (11), 830-840.

[7] Lukin, S.; Stolar, T.; Tireli, M.; Blanco, M. V.; Babić, D.; Friščić, T.; Užarević, K.; Halasz, I. Chem. - A Eur. J. 2017, 23 (56), 13941-13949.

[8] Tremayne, M.; Glidewell, C. Chem. Commun. 2000, 2425-2426. 